\title{
Contribution of Chinese Hot Pot and Barbecue Restaurants on Indoor Environmental Parameters
}

\author{
Yujiao Zhao ${ }^{1,2^{*}}$, Pengfei Tao ${ }^{3}$, Bo Zhang ${ }^{1,2}$, Chao Huan ${ }^{1,2}$ \\ ${ }^{1}$ School of Energy and Resource, Xi'an University of Science and Technology, Xi'an 710054, China \\ ${ }^{2}$ Key Laboratory of Western Mines and Hazards Prevention, Ministry of Education of China, Xi'an 710054, China \\ ${ }^{3}$ Key Laboratory of Coal Resources Exploration and Comprehensive Utilization, Xi'an 710021, China
}

\begin{abstract}
The indoor environmental quality of hot pot and barbecue restaurants has caused an increasing amount of public concern. Hence, this study assessed the conditions and ventilation systems in nine such restaurants of Xi'an, China, by performing field measurements focusing on the variations in temperature, relative humidity, and $\mathrm{CO}$ and $\mathrm{CO}_{2}$ concentrations due to cooking style. The results showed that the indoor environmental quality of the test restaurants depended mainly on the cooking fuel, cooking method and ventilation system. Boiling food in soup (hot pot) raised the relative humidity inside the restaurants. However, without sufficient ventilation, cooking with radiation (hot pot/barbecue) resulted in high personal heat exposure and low relative humidity near the heat sources. A substantial rise in the CO level was observed with the burning of charcoal, whereas an increase in the $\mathrm{CO}_{2}$ concentration was detected with the combustion of natural gas. Furthermore, the operational condition of the kitchen ventilation significantly affected the air quality in the dining area, which was found to be the worst at the restaurant exhibiting the poorest ventilation (i.e., the lowest contaminant removal and heat removal efficiencies). Thus, a more efficient and energy-saving ventilation system for hot pot and barbecue restaurants should be developed.
\end{abstract}

Keywords: Ventilation; Indoor environmental quality; Restaurant; Hot pot cooking; Barbecue cooking; Field test.

\section{INTRODUCTION}

According to the World Health Organization (WHO), approximately millions of people die each year from indoor air pollution (WHO, 2014). Cooking is one of the most important sources of non-smoking air pollution in buildings. Cooking processes generate numerous substances, such as carbon monoxide $(\mathrm{CO})$, carbon dioxide $\left(\mathrm{CO}_{2}\right)$, nitrogen oxides $\left(\mathrm{NO}_{x}\right)$, volatile organic compounds (VOCs), particulate matter (PM), liquid oil droplets and water vapor (Karimatu et al., 2013). The toxic pollutants contained in cooking fumes such as polycyclic aromatic hydrocarbons (PAHs), benzopyrene and others can seriously harm the health of cooks and family members (Chen et al., 2019). Epidemiological studies revealed that exposure to cooking oil fumes increases the morbidity of respiratory tract infections, pneumonia, lung cancer, asthma, kidney disease, cataracts and cardiovascular diseases (Zhang et al., 2017). Oil fumes generated from high-temperature frying are classified as probable carcinogens by the International Agency for Research on Cancer (IARC

\footnotetext{
* Corresponding author.

E-mail address: zhaoyujiao@xust.edu.cn
}

Working Group on the Evaluation of Carcinogenic Risks to Humans, 2010). Cooks are more likely to develop diseases such as lung cancer, nasopharyngeal cancer and esophageal cancer due to long exposure to cooking fumes (Wang et al., 2017a). In China, traditional cooking activity produces more pollutants. Thus, Chinese women rarely smoke but have a high risk of lung cancer (Wang et al., 2017b; Zhang et al., 2017).

Cooking fumes are generated from both food cooking behavior and fuel combustion. The composition of cooking fumes is highly diverse and depends on factors such as cooking styles, raw materials, cooking temperature, heat sources and cooking fuels (Cheng et al., 2016; de la Sota et al., 2019; Que et al., 2019). Some studies suggest that the cooking methods using oil as heat transfer medium, such as barbecue, deep-frying and stir-frying, produce more pollutants than the cooking methods using water as heat transfer medium (steaming, boiling, etc.) (Zhao et al., 2019; Chen et al., 2020). For example, steel-pan-grilling Chinese-style food is capable of elevating submicron particle concentrations up to 5 times higher than European-style cooking (Levy et al., 2002; He et al., 2004). However, in addition to barbecue restaurants, hot pot restaurants have also been measured for relatively high concentrations of $\mathrm{CO}, \mathrm{CO}_{2}$ and $\mathrm{PM}$ (Chen et al., 2007; Lee et al., 2011). At present, limited information 
is available in the published literature. Substantial attention should be paid to the indoor environmental quality of Chinese hot pot and barbecue restaurants.

Cooking with fuels is a main source of air pollution and a leading contributor to disease burden (Ni et al., 2016). Several fuels are used for cooking, including biomass (e.g., charcoal and wood), natural gas, electricity, liquefied petroleum gas and solid alcohol. Natural gas and electricity are the main fuels used in Chinese modern kitchen cooking. Because charcoal and solid alcohol have many advantages, including a higher energy content, the ability to burn evenly for a long time, easier handling, and easily extinguished and reheated, they have been widely used in Chinese barbecue (Susaya et al., 2010). Charcoal combustion is an important source of gaseous (e.g., $\mathrm{CO}, \mathrm{NO}_{x}$ and TVOC) and particulate matter emissions (Vicente et al., 2018). Huang et al. (2016) investigated ten types of the commercial charcoal that is commonly employed in Taiwan's barbecue restaurants. The results suggested that the adverse effects of the large amounts of air pollutants generated during indoor charcoal combustion on health and indoor air quality must not be disregarded (Huang et al., 2016).

Previous studies primarily focused on the exposure of gaseous pollutants and particulates that occur when eating hot pots and barbecues, with less attention placed on the ventilation systems in restaurants. We should realize that the use of an efficient ventilation system is essential to ensuring a healthy, comfortable, productive and energy-efficient environment in a restaurant (Livchak et al., 2005; Tsai and Hsieh, 2006; Li et al., 2012). The effect of air volume, appliances' position, front overhang, rear seals, side panels, separation plate, baffle plate, mannequin and systematic inspections were investigated and quantified on the performance of kitchen exhaust hood (Keil et al., 2004; Swierczyna et al., 2006; Lim and Lee, 2008; Zhao et al., 2013). Many designers and engineers have the misconception that the bad indoor air quality in kitchens is only related to the exhaust hood and disregard the effects of air distribution on hood performance. Supply air strategies, including ceiling supply, capture jet, air curtain, push-pull and displacement ventilation systems, have a significant influence on the pollutant removal effectiveness in a kitchen environment (Kosonen, 2007; Li et al., 2014; Claeys et al., 2015; Zhou et al., 2016).

In the majority of kitchens, the environment is warm to hot (Simone et al., 2013). In a Chinese commercial kitchen, the air temperatures tend to exceed $40^{\circ} \mathrm{C}$. As a result of cooking methods, the relative humidity value in these kitchens significantly varies from $27.5 \%$ to $75 \%$ (Li et al., 2012). Cooks, whose thermal comfort and working efficiency are affected, generally need to work continuously for more than 4 hours in hot and dry/humid environments. Air temperature, relative humidity, air velocity and average radiant temperature are the main factors that affect thermal comfort. $\mathrm{CO}$ is a representative product of incomplete combustion of charcoal. $\mathrm{CO}_{2}$ was often chosen as the main indicator for evaluating contaminants' distribution characteristics and the performances of ventilation systems because the change in the concentration of $\mathrm{CO}_{2}$ as a result of cooking was significant, which facilitate the observation of changes in values (Saha et al., 2012). When the indoor air temperature, relative humidity and $\mathrm{CO}_{2}$ concentrations are maintained within the standardrecommended range, the indoor air quality can be improved.

Due to a lack of cooking source of pollution in dining areas, evaluation of the ventilation systems in restaurants was often disregarded in the literature. For hot pot or barbecue restaurants, the assessment of a ventilation system in a dining area is essential. None of the existing standards are specially tailored for the ventilation system design in typical Chinese hot pot or barbecue restaurants. In practice, empirical knowledge of existing installations has been employed for ventilation system determination. The actual working condition of the ventilation systems of Chinese hot pot and barbecue restaurants remains unknown. To improve the indoor environmental quality in typical Chinese-style hot pot and barbecue restaurants and assess their ventilation systems while customers are eating hot pot and barbecue, a study was undertaken in nine traditional restaurants, including five hot pot restaurants and four barbecue restaurants, in Xi'an, China.

\section{METHOD}

\section{Restaurants}

Five Chinese traditional hot pot $(\mathrm{H})$ restaurants and four barbecue (B) restaurants were selected in July, the hottest time of the year. All the restaurants are located in an urban commercial area with high traffic density. No open chimneys or other sources of air pollution were noted nearby. Restaurants H1, $\mathrm{H} 2$ and $\mathrm{H} 5$ provide the typical Changing má là ("numb and spicy") hot pot, which is one of the most popular foods in China. A considerable amount of Sichuan pepper combined with spicy ingredients such as chili is added to the broth. Restaurants H3 and H4 provide fish hot pot, which contains cooked fish. Unlike the Chungking má là hot pot, the pot does not contain broth at the beginning of the meal. While the fish is heating, other hot pot dishes and broth can be loaded into the pot. Restaurants B1 and B2 provide Korean-style barbecue. In Restaurants B3 and B4, it is served traditional Chinese-style barbecue. During the process of baking, cooking oil is continuously brushed on a hot steel pan to enhance the flavor of the food.

The scales of the dining areas of the nine restaurants exceed $138 \mathrm{~m}^{2}$, and all restaurants have mixed air conditioning systems. The total ventilation rate of all restaurants is designed according to the air change rate $\left(15 \mathrm{~h}^{-1}\right)$. The ventilation rate $=$ the air change rate $\times$ the room volume. In Restaurants $\mathrm{H} 2$, B1 and B2, a cooking pot or steel pan is sunk into a table with a slot exhaust outlet on the edges of the table. In this case, $80 \%$ of the total ventilation rate is used for local ventilation, that is, the local ventilation rate is 12 times $\mathrm{h}^{-1}$ and the general ventilation is 3 times $\mathrm{h}^{-1}$. In other restaurants, the cooking pot or steel pan is placed on a table without local exhaust ventilation. A photograph of the side exhaust outlet on the edges of the table in Restaurant $\mathrm{H} 2$ is shown in Fig. 1. The floor plans of the case-study restaurants are shown in Fig. 2. 


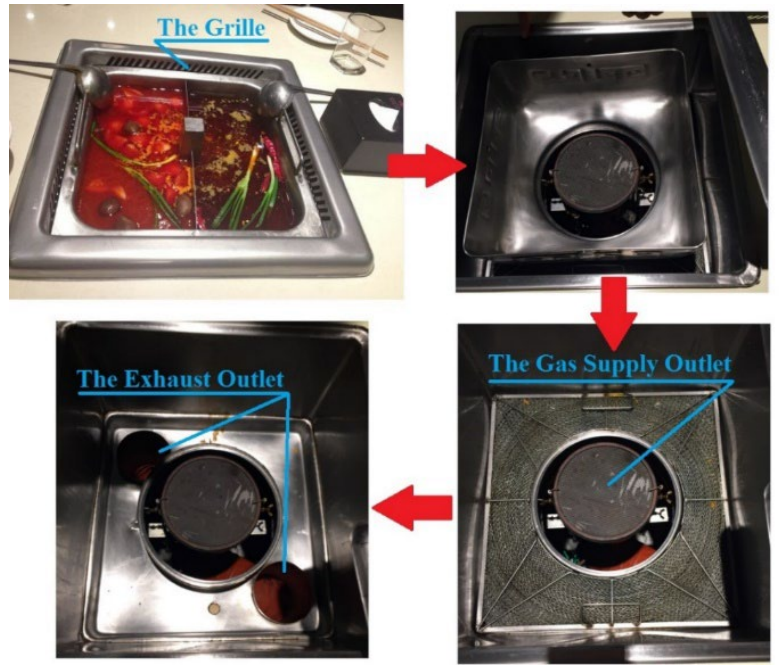

Fig. 1. A photograph of the side exhaust outlet of the hot pot in Restaurant H2.

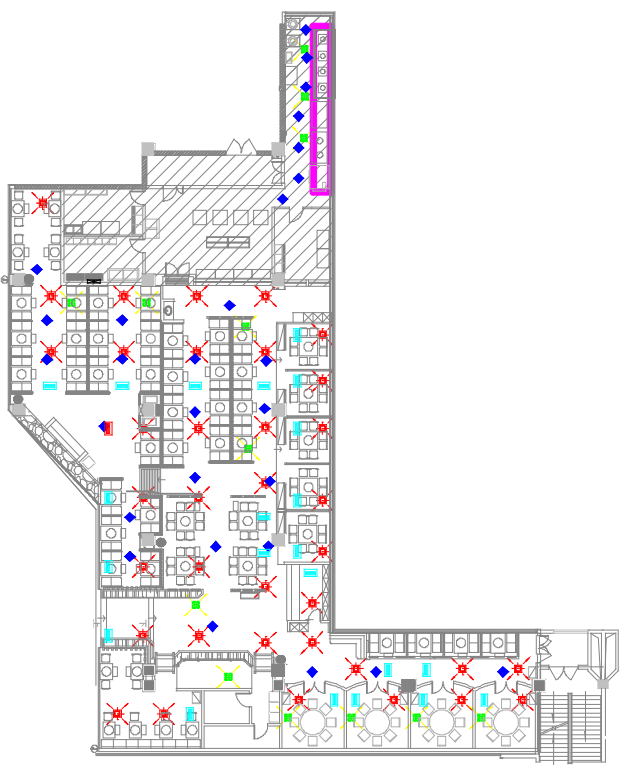

(a)

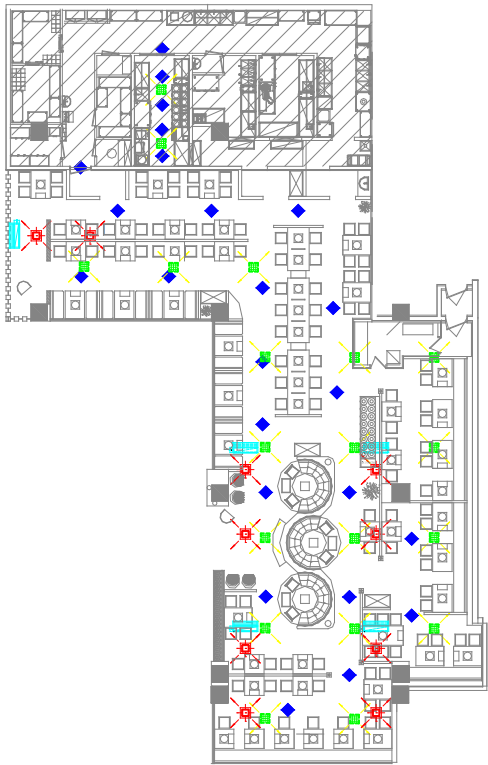

(c)

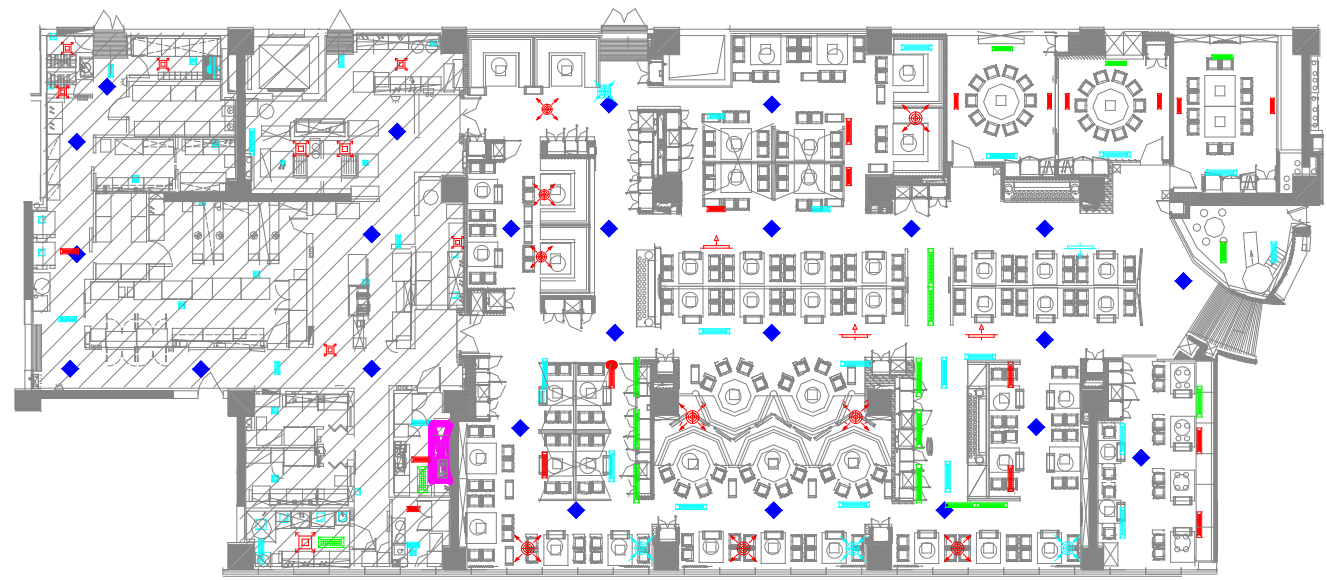

(b)

Fig. 2. Floor plan of the case-study restaurants (the shaded areas are the kitchens): (a) Restaurant H1, (b) Restaurant H2, (c) Restaurant H3, (d) Restaurant H4, (e) Restaurant H5, (f) Restaurant B1, (g) Restaurant B2, (h) Restaurant B3 and (i) Restaurant B4. 


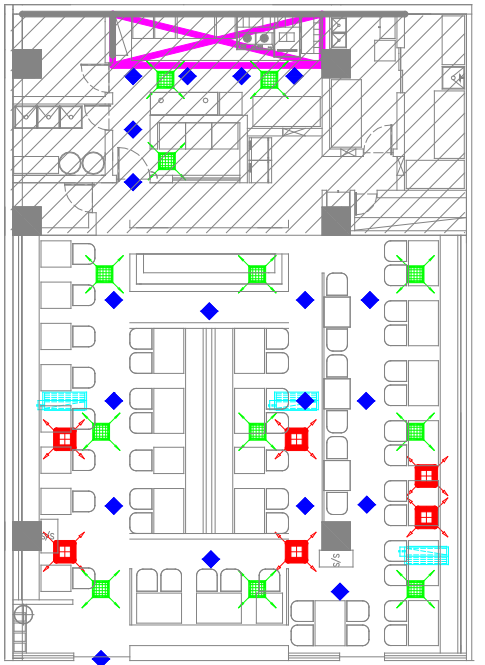

(d)

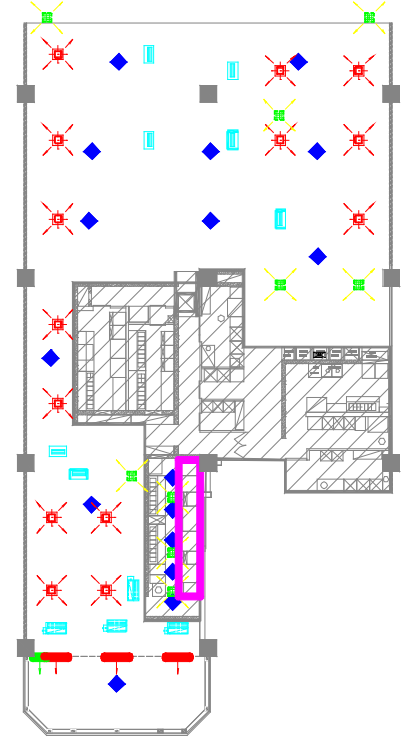

(f)

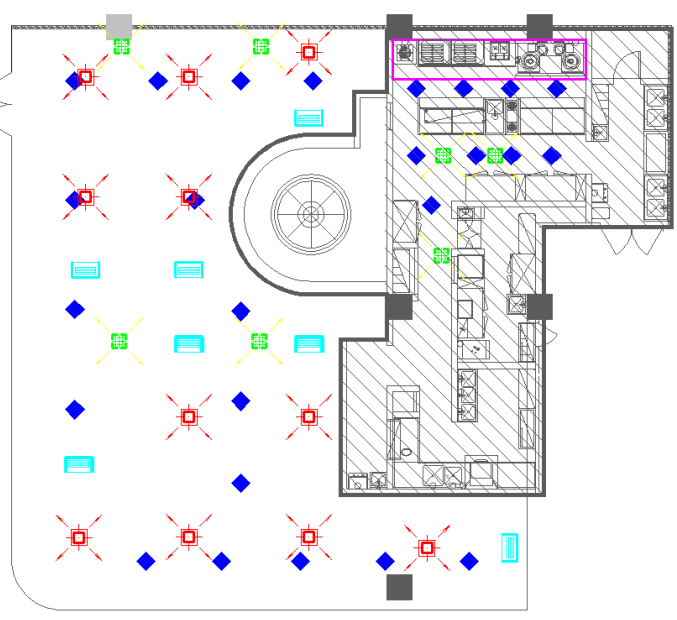

(h)

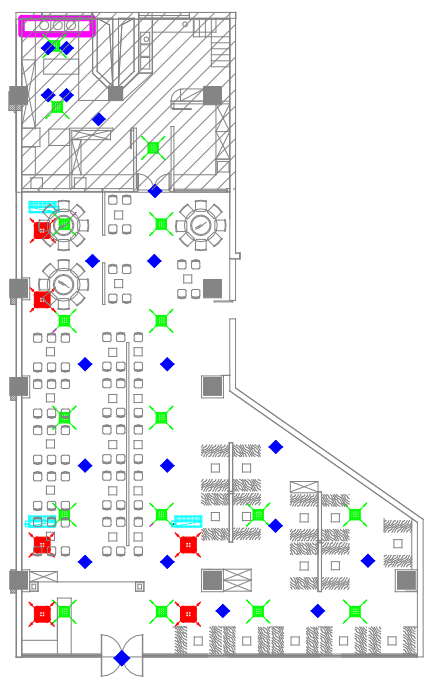

(e)

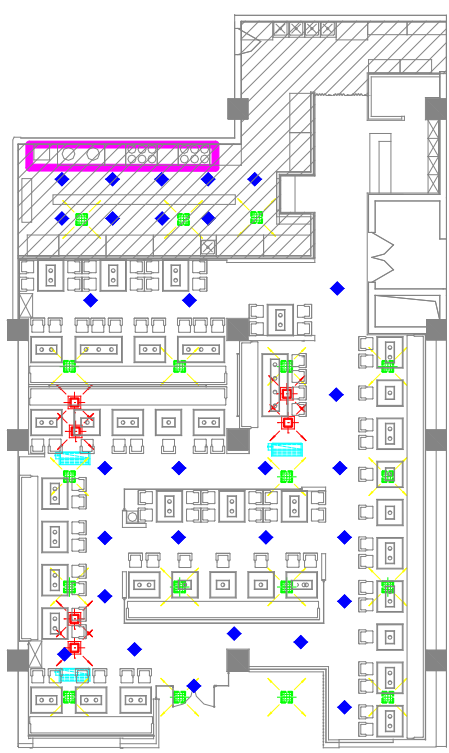

(g)

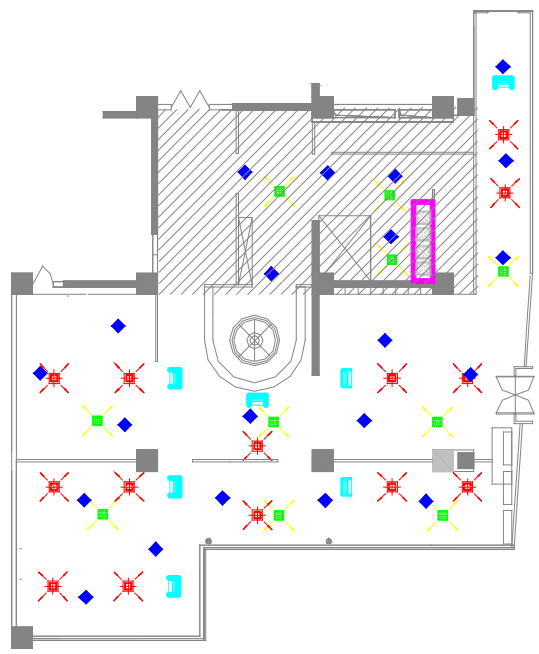

(i) 
The kitchen areas of the nine restaurants exceed $50 \mathrm{~m}^{2}$. In this study, we mainly focused on the environmental quality of the cooking (hot working) area, where a considerable amount of heat and air pollutants are generated. The floor plans of the hot working areas of the case-study kitchens are shown in Fig. 3. H2 is a chain hot pot restaurant. Many ingredients are prepared and shipped to the kitchen for storage, so there is no need for a large number of open-fire operations. Although the kitchen is large, there is no hot cooking area, so the floor plan is not shown in Fig. 3. The cooking ranges of these kitchens are located in a line that backs up to a wall; this setup is a typical arrangement in Chinese commercial kitchens. The cooking ranges are installed under a wall-mounted canopy hood, with the exception of Kitchens $\mathrm{H} 2$ and $\mathrm{H} 3$. The designed ventilation rate of the exhaust hood is $60 \mathrm{~h}^{-1}$. The front lower edges of the hoods of the seven kitchens are located $1.8 \mathrm{~m}$ from the finished floor, as measured vertically. The front edge of the hood is designed to be at an angle of approximately $45^{\circ}$, which is substantially different from American or European methods (Li et al., 2012).

General characteristics of these restaurants are listed in Tables 1-4. Two parameters can be used to characterize the impact of the number of diners on the contribution of indoor $\mathrm{CO}_{2}$ in dining room, namely, the diner number per unit dining area $(\mathrm{s})$ and the heat source number per each diner $(\mathrm{k})$.

$s=\frac{\text { number of diners }}{\text { dining area }}$

$$
k=\frac{\text { number of heat sources }}{\text { number of diners }}
$$

\section{Test Parameters}

In this study, the designed exhaust air flow rates of the restaurants were determined by the air change rate method, where the air flow rate was calculated by the selected air change rate $\left(15 \mathrm{~h}^{-1}\right)$ and the volume of the restaurants. The capture velocity of the exhaust hood was measured according to the surface air velocity method in AQ/T 4274-2016. We cut a hole in the supply/exhaust air duct above the ceiling and placed the probes through the hole to test the supply/exhaust air parameters. During the tests, the power of the cooking ranges was determined by the consumed quantity of the fuels and the corresponding calorific value. The energy consumption information was provided by the restaurant managers. In this study, the number of heat sources and diners was based on field statistics. The designed cooling load and exhaust air flow rate were provided by the China Northwest Architecture Design and Research Institute.

\section{Sampling Point}

Each restaurant was divided into two test sections: the dining area and kitchen. The sampling points were placed at $1.1 \mathrm{~m}$ (dining area) and $1.5 \mathrm{~m}$ (kitchen) above the floor and far from potential sources of air pollutants in each sampling location. For a single hot pot or steel pan (heat source), the thermal plume was measured at $0.5 \mathrm{~m}$ and $1 \mathrm{~m}$ above the table. The sampling numbers and the setup of the sampling points are illustrated in Table 5, Figs. 2, 3 and 4. The measurements were performed during non-meal time (10-11 a.m.) and meal time (1:00-2:00 p.m. or 7:00-8:00 p.m.) to reflect their difference. The sampling time of each restaurant was not more than 1 hour, so as to minimize the impact of changes on the diners. A sample was collected outdoors at a height of $1.5 \mathrm{~m}$ in close proximity to the fresh air intake. Simultaneous indoor and outdoor air sampling was performed at each sampling site. No smoking activities were observed in these restaurants during air sampling.

\section{Test Instruments and Error Analysis}

Measurements were simultaneously conducted at the sampling points of the dining area, kitchen and outdoors; thus, three sets of test identical instruments were employed in this study. Air velocity, temperature and relative humidity were measured with the calibrated VelociCalc $\AA$ Plus MultiParameter Ventilation Meter (Model 8386A; TSI Inc.). $\mathrm{CO}_{2}$ and $\mathrm{CO}$ concentrations were measured with the IAQ-Calc ${ }^{\mathrm{TM}}$ Indoor Air Quality Meter (Model 7545; TSI Inc.) and were tested and calibrated with a calibration gas of known concentration. Pre- and post-zero checking of the monitors was performed. The ranges and limits of the detection of the analytical methods are summarized in Table 6 . The data of each sampling point were read with a delay time of 10 seconds to eliminate possible mechanical fluctuations in the probe movement. Instantaneous data measurements were taken every second; these measurements were recorded over a period of at least 1 minute to give the reported value prior to moving to the next sampling point. Each restaurant repeated the test two times on different days. Duplicated indoor and outdoor samples were collected at these restaurants to ensure the repeatability and consistency of the sampling data. The standard deviation (SD) was used to evaluate the sampling precision.

\section{RESULTS AND DISCUSSION}

\section{Measurements of Dining Areas}

Fig. 5 presents the indoor levels of the targeted parameters generated from the dining areas of the nine restaurants. From Fig. 5, we were able to determine that the indoor environmental quality of the sampled restaurants was related to the fuel of the heat sources and the mechanical exhaust system, especially the local exhaust system. The data in Fig. 5(a) indicates minimal difference between the mean temperatures of the dining areas before and after a meal. Because the supply air temperatures of Restaurants $\mathrm{H} 1, \mathrm{~B} 2$ and $\mathrm{B} 3$ were reduced to $20^{\circ} \mathrm{C}$ at dinner time, the indoor average temperatures also decreased. Fig. 5(b) revealed a higher level in the mean values of relative humidity in the dining areas after a meal. The increase in the average relative humidity in hot pot restaurants was larger than $8.2 \%$, whereas it was less than $4.4 \%$ in the barbecue restaurants, with the exception of Restaurant B1. This result was primarily related to the catering mode in the hot pot restaurants, during which the broth was maintained in a boiling state for as long as 1-2 hours of the 


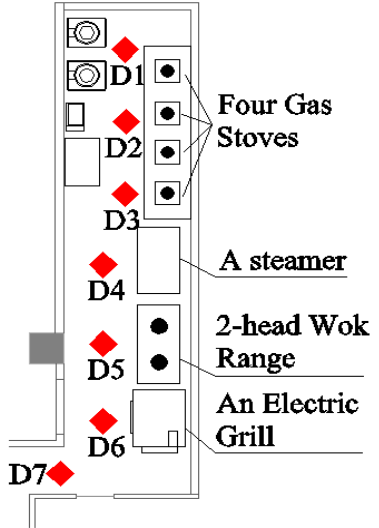

(a)

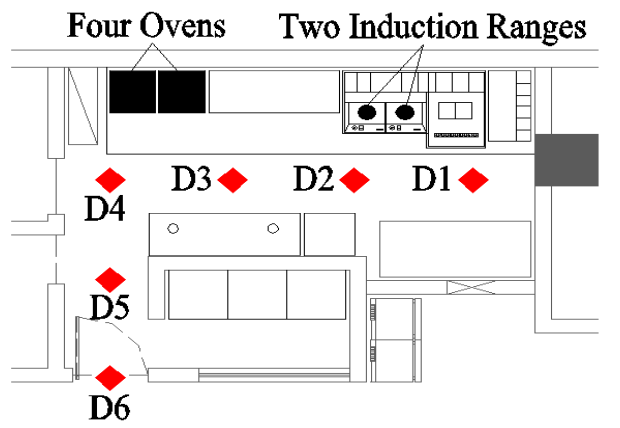

(c)

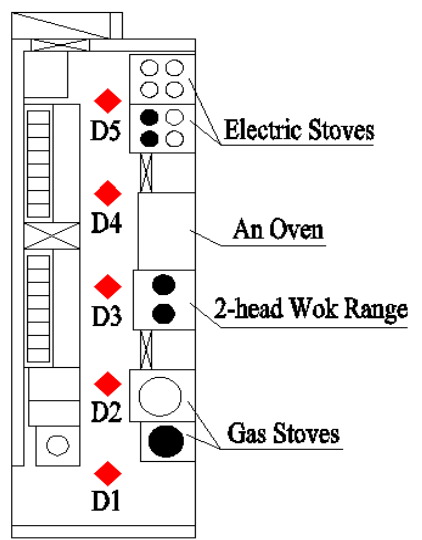

(e)

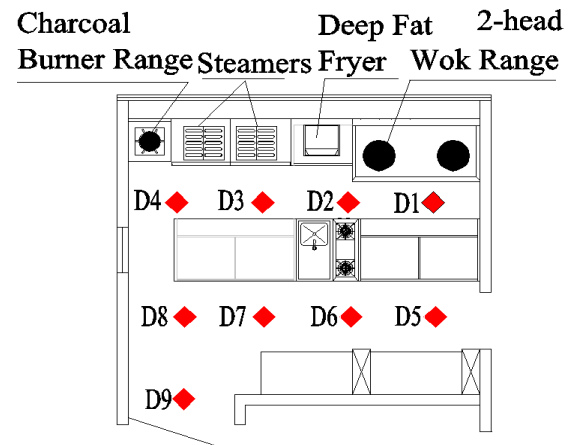

(g)

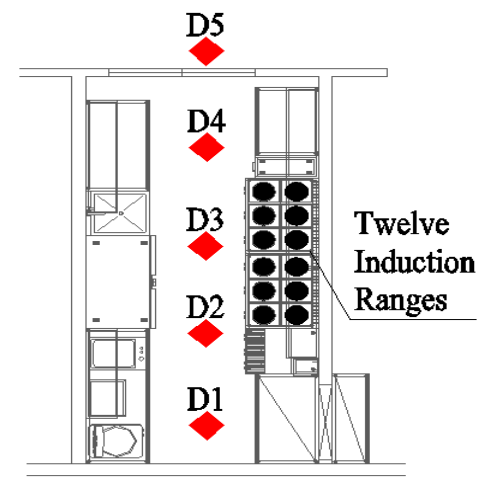

(b)

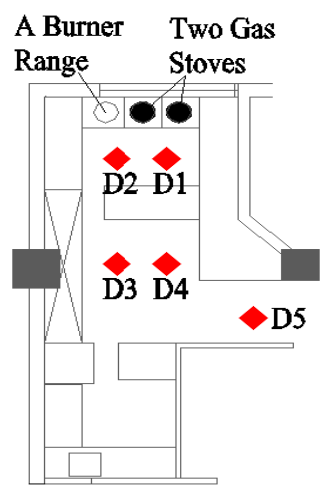

(d)

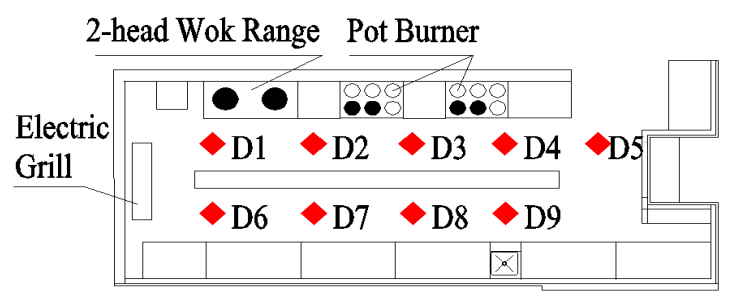

(f)

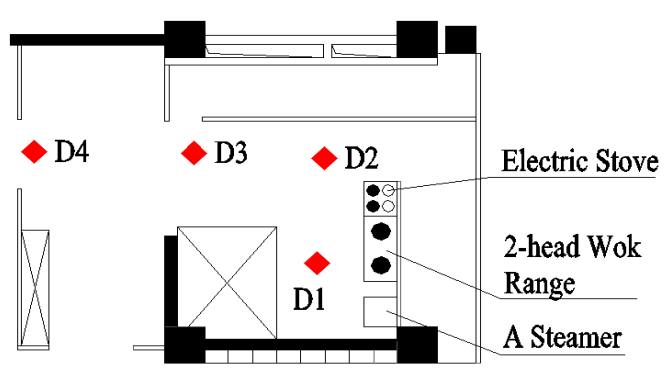

(h)

Fig. 3. Floor plan of the hot working area of case-study kitchens and the layout of the sampling points: (a) Kitchen H1, (b) Kitchen H3, (c) Kitchen H4, (d) Kitchen H5, (e) Kitchen B1, (f) Kitchen B2, (g) Kitchen B3 and (h) Kitchen B4. (The black range indicates that it was burning during the cooking time.) 
Table 1. Main background data of dining areas in sampled restaurants.

\begin{tabular}{|c|c|c|c|c|c|c|c|c|c|}
\hline $\begin{array}{l}\text { Dining } \\
\text { room }\end{array}$ & $\begin{array}{l}\text { Area } \\
\left(\mathrm{m}^{2}\right)\end{array}$ & $\begin{array}{l}\text { Number } \\
\text { of diners }\end{array}$ & $\left(\# \mathrm{~m}^{-1}\right)$ & $\begin{array}{l}\text { Number } \\
\text { of heat } \\
\text { sources }\end{array}$ & $\mathrm{k}$ & $\begin{array}{l}\text { Power of } \\
\text { each pot/ } \\
\text { steel pan } \\
(\mathrm{kW})\end{array}$ & $\begin{array}{l}\text { Fuel type/chemical } \\
\text { composition }\end{array}$ & $\begin{array}{l}\text { Designed } \\
\text { cooling } \\
(\mathrm{kW})\end{array}$ & $\begin{array}{l}\text { Designed } \\
\text { exhaust } \\
\text { air flow rate } \\
\left(\mathrm{m}^{3} \mathrm{~h}^{-1}\right)\end{array}$ \\
\hline H1 & 497 & 220 & 0.42 & 54 & 0.25 & 3.8 & $\mathrm{Gas} / \mathrm{CH}_{4}$ & 280 & 22,420 \\
\hline $\mathrm{H} 2$ & 539 & 250 & 0.46 & 61 & 0.24 & 3.8 & $\mathrm{Gas} / \mathrm{CH}_{4}$ & 310 & $6400 / 34,140^{a}$ \\
\hline H3 & 345 & 182 & 0.53 & 57 & 0.31 & 1.8 & Electricity & 150 & 12,420 \\
\hline $\mathrm{H} 4$ & 168 & 92 & 0.55 & 31 & 0.34 & 1.5 & Electricity & 60 & 5000 \\
\hline H5 & 257 & 130 & 0.51 & 37 & 0.28 & 2.0 & Electricity & 110 & 8020 \\
\hline B1 & 293 & 144 & 0.49 & 29 & 0.2 & 0.8 & Electricity & 180 & $3950 / 15,800^{a}$ \\
\hline B2 & 253 & 138 & 0.54 & 38 & 0.28 & 0.8 & Electricity & 160 & $3500 / 14,000^{\mathrm{a}}$ \\
\hline B3 & 286 & 130 & 0.45 & 38 & 0.29 & $0.9^{\mathrm{b}}$ & Charcoal/C & 132 & 15,015 \\
\hline B4 & 350 & 188 & 0.54 & 47 & 0.25 & $1.25^{\mathrm{c}}$ & Solid alcohol $/ \mathrm{C}_{2} \mathrm{H}_{5} \mathrm{OH}$ & 150 & 12,600 \\
\hline
\end{tabular}

a General ventilation/side exhaust ventilation.

${ }^{\mathrm{b}}$ The calorific value of charcoal is $8500\left(\mathrm{kcal} \mathrm{kg}^{-1}\right)$.

c The calorific value of alcohol is $30,000\left(\mathrm{~kJ} \mathrm{~kg}^{-1}\right)$.

Table 2. Main background data of kitchens in sampled restaurants.

\begin{tabular}{|c|c|c|c|c|c|c|c|}
\hline Kitchen & $\begin{array}{l}\text { Total area } \\
\left(\mathrm{m}^{2}\right)\end{array}$ & $\begin{array}{l}\text { Hot } \\
\text { working } \\
\text { area } \\
\left(\mathrm{m}^{2}\right)\end{array}$ & $\begin{array}{l}\text { Power of } \\
\text { cooking } \\
\text { ranges }(\mathrm{kW})\end{array}$ & $\begin{array}{l}\text { Fuel type/ } \\
\text { chemical } \\
\text { composition }\end{array}$ & $\begin{array}{l}\text { Designed } \\
\text { exhaust air } \\
\text { flow rate } \\
\left(\mathrm{m}^{3} \mathrm{~h}^{-1}\right)\end{array}$ & $\begin{array}{l}\text { Energy use } \\
\text { (per meal) }\end{array}$ & $\begin{array}{l}\text { Actual } \\
\text { capture } \\
\text { velocity } \\
\text { of hood } \\
\left(\mathrm{m} \mathrm{s}^{-1}\right)\end{array}$ \\
\hline H1 & 169 & 38 & 20.2 & $\mathrm{Gas} / \mathrm{CH}_{4}$ & 1,0000 & $33 \mathrm{~m}^{3}$ & 0.1 \\
\hline $\mathrm{H} 2$ & 273 & - & - & Electricity & 15,000 & $105 \mathrm{~kW} \mathrm{~h}$ & - \\
\hline H3 & 120 & 13 & 24.2 & Electricity & 7200 & $75 \mathrm{~kW} \mathrm{~h}$ & - \\
\hline H4 & 70 & 16 & 26.2 & Electricity & 4200 & $65 \mathrm{~kW} \mathrm{~h}$ & 0.53 \\
\hline H5 & 71 & 18 & 1.65 & $\mathrm{Gas} / \mathrm{CH}_{4}$ & 5260 & $25 \mathrm{~m}^{3}$ & 0.8 \\
\hline B1 & 119 & 15 & 24.3 & $\mathrm{Gas} / \mathrm{CH}_{4}$ & 2800 & $15 \mathrm{~m}^{3}$ & 1.5 \\
\hline B2 & 65 & 40 & 31.0 & $\mathrm{Gas} / \mathrm{CH}_{4}$ & 3900 & $14 \mathrm{~m}^{3}$ & 1.2 \\
\hline B3 & 60 & 29 & 16.5 & $\mathrm{Gas} / \mathrm{CH}_{4} \mathrm{charcoal} / \mathrm{C}$ & 2220 & $18 \mathrm{~m}^{3} / 50 \mathrm{~kg}$ & 0.79 \\
\hline B4 & 50 & 20 & 25.0 & $\mathrm{Gas} / \mathrm{CH}_{4}$ & 3000 & $20 \mathrm{~m}^{3}$ & 0.7 \\
\hline
\end{tabular}

Table 3. General comparisons of the ventilation system of sampled restaurants ${ }^{\mathrm{a}}$.

\begin{tabular}{lll}
\hline Restaurant & Dining room & Kitchen \\
\hline H1 & FCU + PAU & LEV + PAU \\
H2 & VRV + PAU + LEV & LEV + PAU + VRV \\
H3 & FCU + PAU & FCU + PAU \\
H4 & FCU + PAU & LEV + PAU \\
H5 & FCU + PAU & LEV \\
B1 & VRV + PAU + LEV & LEV + PAU \\
B2 & FCU + PAU + LEV & LEV + PAU \\
B3 & VRV + PAU & LEV + PAU \\
B4 & FCU + PAU & LEV + PAU \\
\hline
\end{tabular}

${ }^{a}$ VRV: variable refrigerant volume; FCU: fan coil unit; PAU: primary air unit; LEV: local exhaust ventilation; NAS: natural air supply.

dining time. Due to evaporation, the boiled soup needed to be refilled, which enabled a considerable amount of water vapor to evaporate into the surrounding environment and generate a high relative humidity value.

Fig. 5(c) indicates that the $\mathrm{CO}$ concentration in the restaurants was primarily related to the fuel used under the hot pot or steel pan. The largest increase in $\mathrm{CO}$ concentration was detected in Restaurant B3, where charcoal was employed as the fuel. Due to the incomplete combustion of charcoal, the local average $\mathrm{CO}$ concentration in Restaurant B3 increased to $11.8 \mathrm{ppm}$, which was $3.8 \mathrm{ppm}(47.5 \%)$ higher than the acceptable level (8 ppm; GB/T 18883-2002 Indoor Air Quality Standard of China, 2002). The high concentration of $\mathrm{CO}$ can cause significant damage to human body health. The second increase in $\mathrm{CO}$ concentration occurred in the restaurants that used gas as fuel (Restaurant $\mathrm{H} 1$ and H2). Note that the 
Table 4. Air parameters of supply and outdoor.

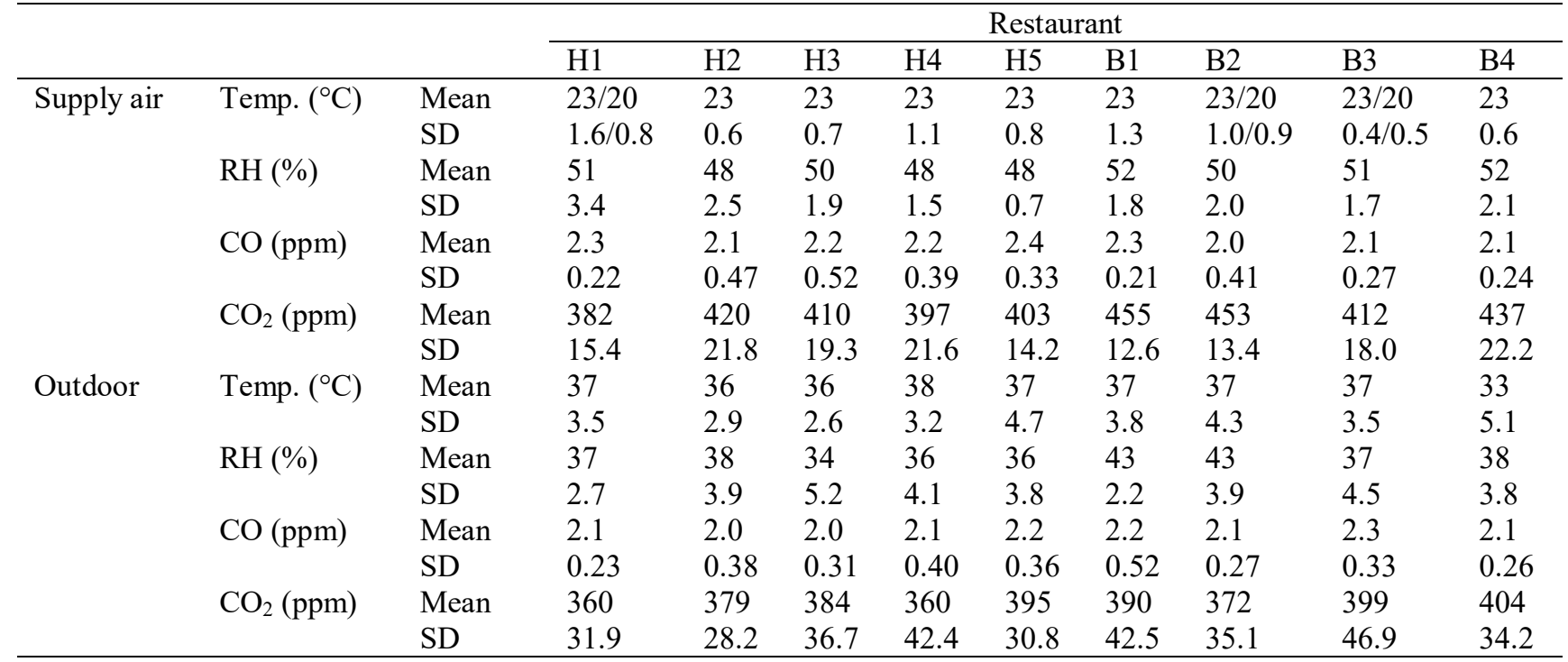

Table 5. Simple numbers of restaurants.

\begin{tabular}{llll}
\hline Restaurant & $\begin{array}{l}\text { Dining } \\
\text { room }\end{array}$ & Kitchen & $\begin{array}{l}\text { Single hot } \\
\text { pot/grill }\end{array}$ \\
\hline H1 & 22 & 7 & - \\
H2 & 17 & 8 & 14 \\
H3 & 18 & 5 & - \\
H4 & 13 & 6 & - \\
H5 & 15 & 5 & - \\
B1 & 11 & 5 & 14 \\
B2 & 20 & 9 & 14 \\
B3 & 16 & 9 & - \\
B4 & 16 & 4 & - \\
\hline
\end{tabular}

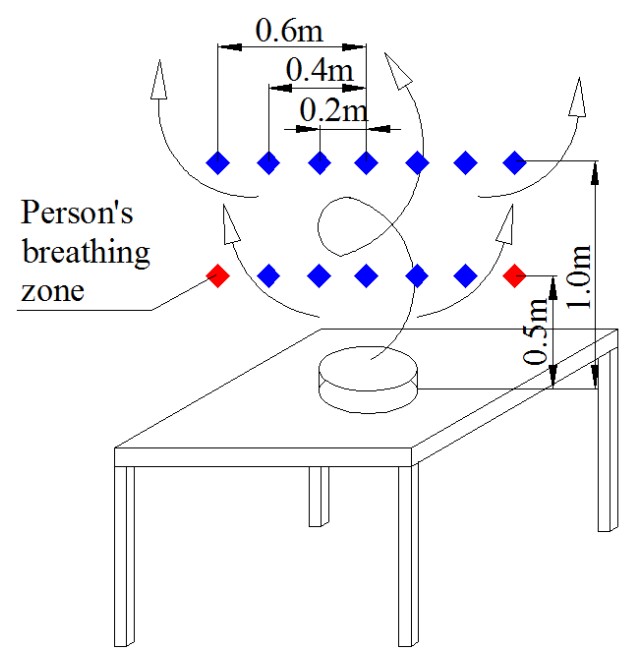

Fig. 4. The layout of the sampling points for a single hot pot/steel grill.

local exhaust system in Restaurant $\mathrm{H} 2$ can effectively exhaust the products of incomplete combustion. Thus, the $\mathrm{CO}$ concentration in Restaurant $\mathrm{H} 2$ was lower than that in Restaurant H1. Because electricity was used as the fuel, CO was not produced in the heating process, which enabled lower $\mathrm{CO}$ values in the dining area of the restaurants. As shown in Fig. 5(d), the generation of $\mathrm{CO}_{2}$ was also related to the fuel combustion. The largest increase in $\mathrm{CO}_{2}$ concentration occurred in the restaurant that used natural gas as fuel (Restaurant $\mathrm{H} 1$ ). The local average $\mathrm{CO}_{2}$ concentration in Restaurant H1 increased to $1673.2 \mathrm{ppm}$, which was $673.2 \mathrm{ppm}$ (67.3\%) higher than the acceptable level (1000 ppm; GB/T 18883-2002 Indoor Air Quality Standard of China, 2002). The second increase of $\mathrm{CO}_{2}$ concentration was detected in the restaurants that use charcoal (Restaurant B3) and solid alcohol (Restaurant B4) as fuel. The smallest increase in $\mathrm{CO}_{2}$ concentration was detected in the restaurants that use electricity as fuel. Lee et al. (2001)'s research revealed that the elevated $\mathrm{CO}_{2}$ levels within the dining areas were attributed to the high occupancy in crowded indoor environments and the operation of combustion sources for cooking without sufficient ventilation. In this study, it can be found that the number of diners in the tested dining rooms per unit area is between 0.44 and 0.55 , while the heat source number per each diner of the nine dining rooms is between 0.2 and 0.33 . In other words, the number of diners in the tested restaurants is evenly distributed, with a similar density and a similar proportion to the cooking heat source. During the test, the $\mathrm{CO}_{2}$ values produced by the people measured at a certain point can be considered to be similar. Therefore, the occupancies in all restaurants were almost equal, which suggested that $\mathrm{CO}_{2}$ is primarily derived from the combustion of fuel. However, with the exception of Restaurant $\mathrm{H} 1$, the $\mathrm{CO}_{2}$ concentrations in the other restaurants did not exceed the Chinese indoor air quality standard. From the available data, the environmental quality in Restaurant H1 was the worst.

To further analyze the poor indoor environmental quality in Restaurant H1, a single heat source (hot pot or steel pan) was selected in Restaurants H1, H2 and B1 to investigate the effect on the local exhaust ventilation system. As shown in Fig. 6, because the cooking pot or steel pan in Restaurants $\mathrm{H} 2$ and $\mathrm{B} 1$ was sunk into the table with a local exhaust 
Table 6. Detection range and limits of tested air parameters.

\begin{tabular}{|c|c|c|c|}
\hline Air parameter & Range & Accuracy & Resolution \\
\hline Temperature $\left({ }^{\circ} \mathrm{C}\right)$ & -10 to 60 & \pm 0.3 & 0.1 \\
\hline Relative humidity (\%) & $0-95$ & \pm 3 & 0.1 \\
\hline Velocity $\left(\mathrm{m} \mathrm{s}^{-1}\right)$ & $0-50$ & $\pm 3 \%$ of reading or $\pm 0.15 \mathrm{~m} \mathrm{~s}^{-1}$ & $0.01 \mathrm{~m} \mathrm{~s}^{-1}$ \\
\hline $\mathrm{CCO}_{2}(\mathrm{ppm})$ & $0-5000$ & $\pm 3 \%$ of reading or $\pm 3 \mathrm{ppm}$, whichever is greater & 1 \\
\hline $\mathrm{CCO}(\mathrm{ppm})$ & $0-500$ & $\pm 3 \%$ of reading or $\pm 50 \mathrm{ppm}$, whichever is greater & 0.1 \\
\hline
\end{tabular}

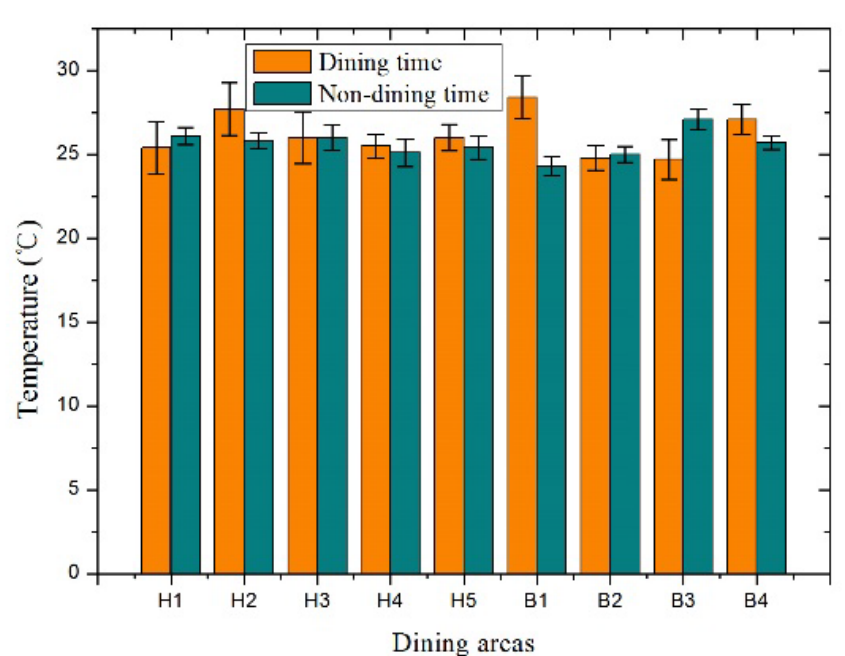

(a)

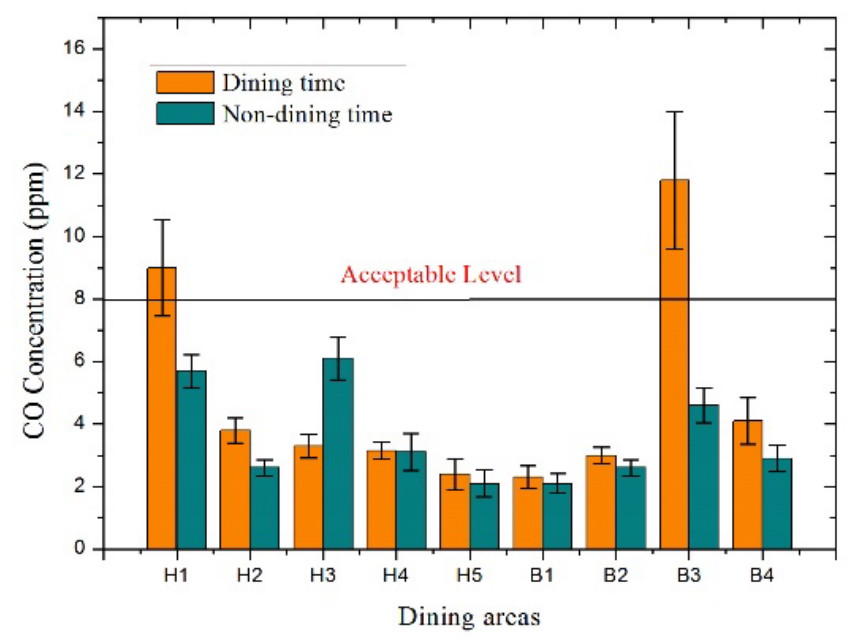

(c)

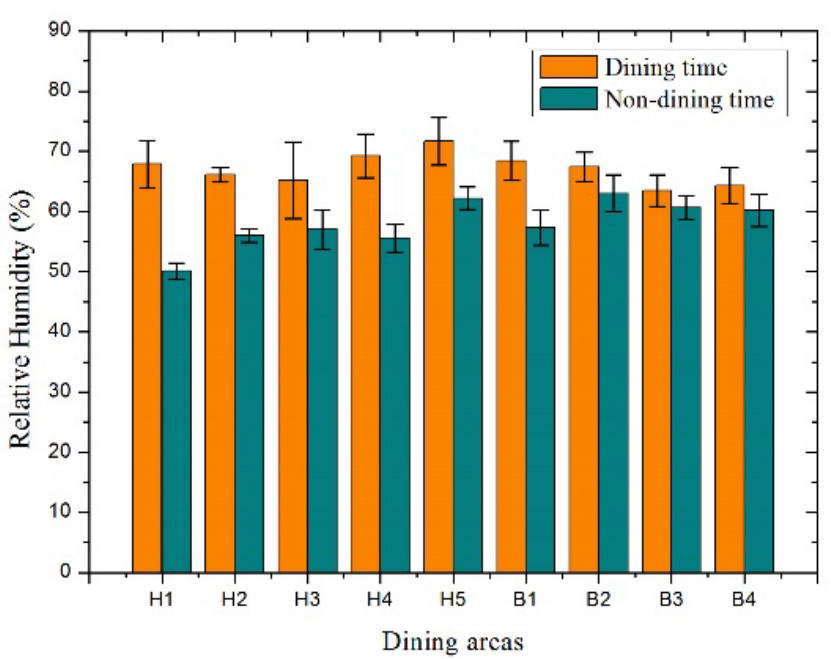

(b)

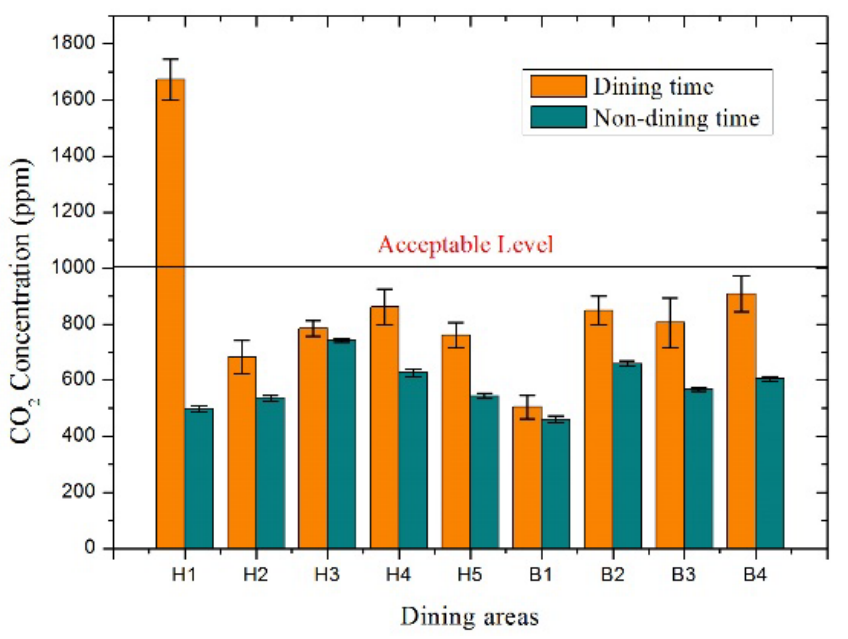

(d)

Fig. 5. Comparison of indoor levels of targeted parameters generated from different dining areas: (a) temperature, (b) relative humidity, (c) $\mathrm{CO}$ concentration and (d) $\mathrm{CO}_{2}$ concentration.

ventilation system, the temperature and contaminant levels above the hot pot (heat source) were relatively low and underwent minimal change during meal time. Conversely, the measurement values in Restaurant $\mathrm{H} 1$ were extremely high because the cooking pot was placed on the table without local exhaust ventilation. Note the air outlet installed on the roof of the private room in Restaurant H1. Thus, the peak values did not appear in the middle of the heat source. In Restaurant $\mathrm{H} 1$, the maximum values of temperature, $\mathrm{CO}$ and $\mathrm{CO}_{2}$ above the hot pot during meal time were $40.9^{\circ} \mathrm{C}, 9.8 \mathrm{ppm}$ and $3340 \mathrm{ppm}$ at $0.5 \mathrm{~m}$ above the table. The distribution of relative humidity was different than other parameters. In Restaurants $\mathrm{H} 2$ and $\mathrm{B} 1$, the values of relative humidity above the hot pot or steel pan underwent minimal change, which ranged from $60.2 \%$ to $68.8 \%$. In Restaurant $\mathrm{H} 1$, the change in relative humidity was significant: The maximum value of $95 \%$ was achieved $0.5 \mathrm{~m}$ above the heat source, whereas the lowest value of only $35.4 \%$ was achieved at the personnel breathing zone beside the table. As a result, during meal time, people were in an environment with hot, dry air and a high concentration of pollutants, and achieving satisfactory thermal comfort and air quality in Restaurant $\mathrm{H} 1$ was difficult. 


\section{Measurements of Kitchens}

Fig. 7 presents the indoor levels of targeted parameters that were generated from the hot working areas of nine

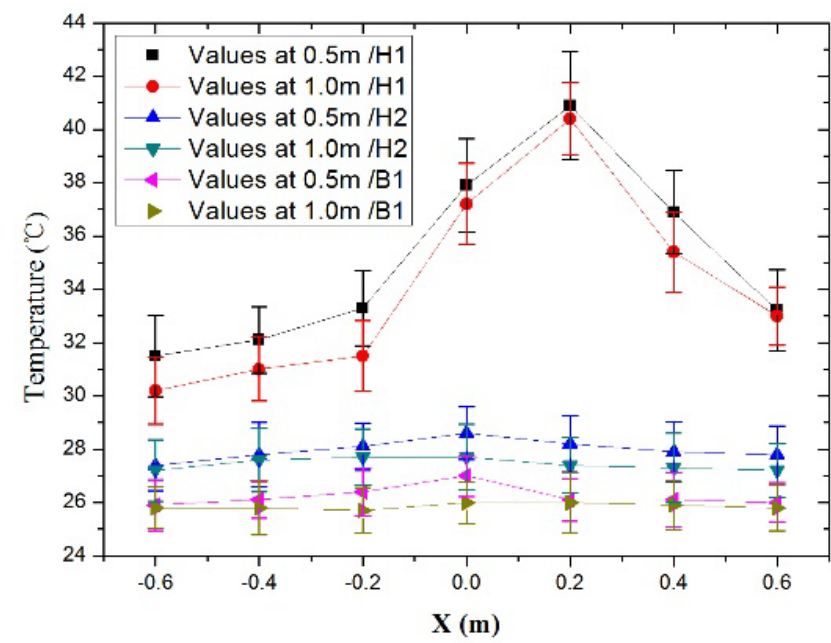

(a)

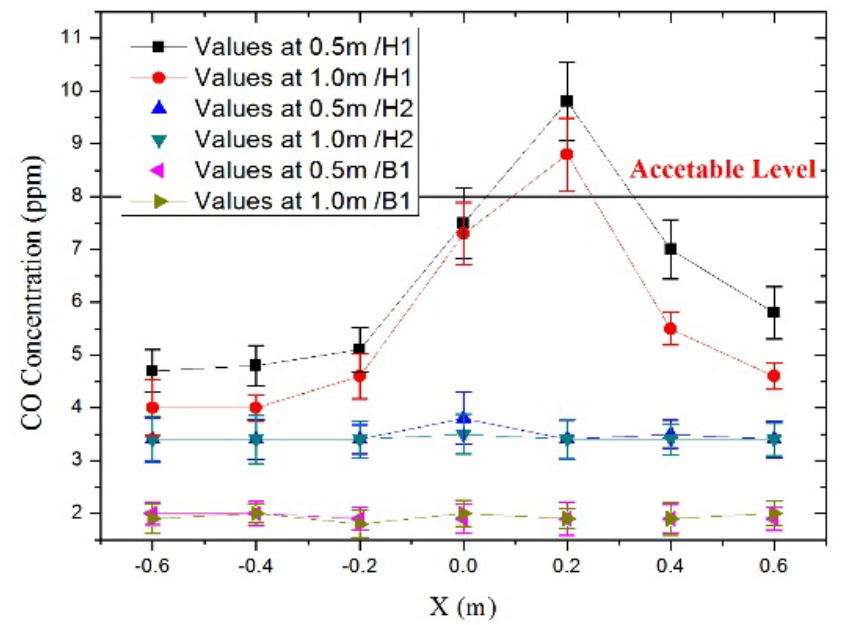

(c) restaurants. From Fig. 7, we were able to determine that the indoor environmental quality of the sampled kitchens was related to the fuel, cooking method and the exhaust hood

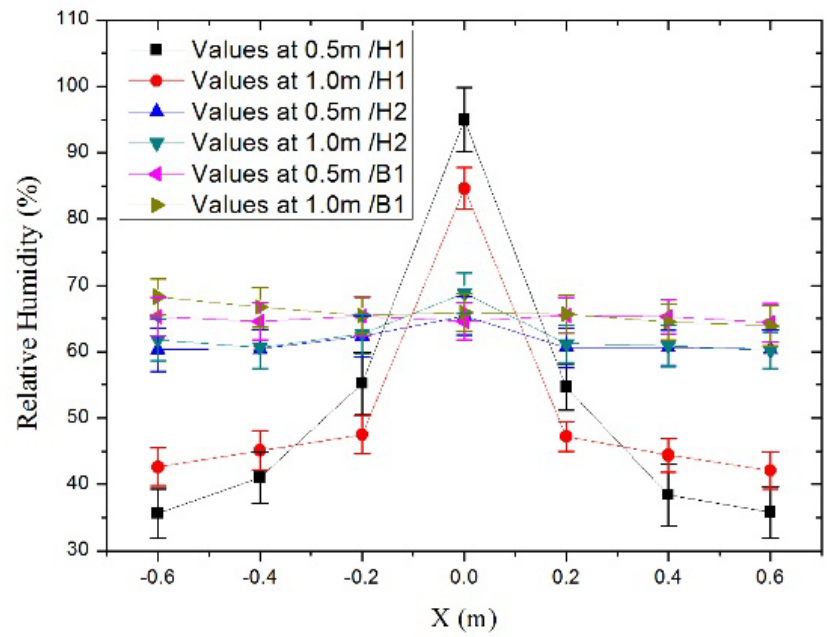

(b)

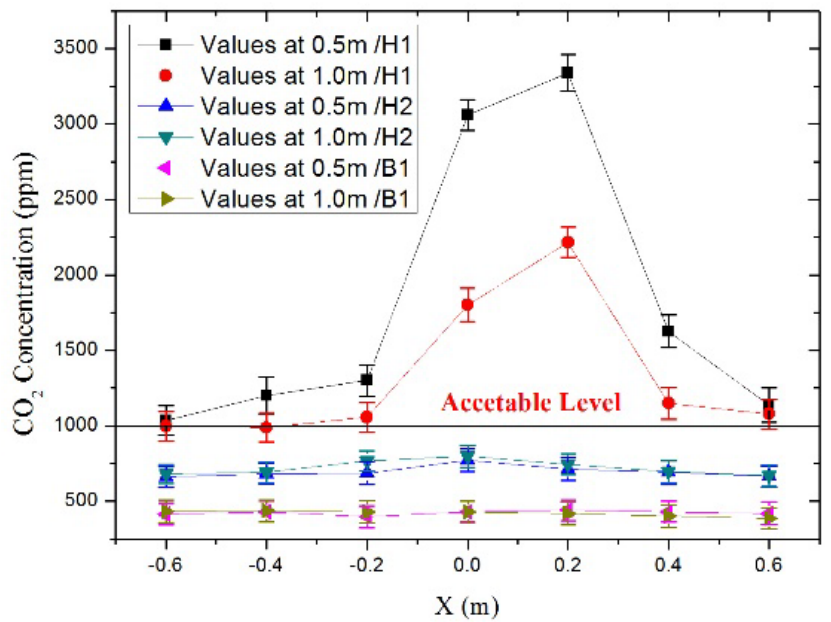

(d)

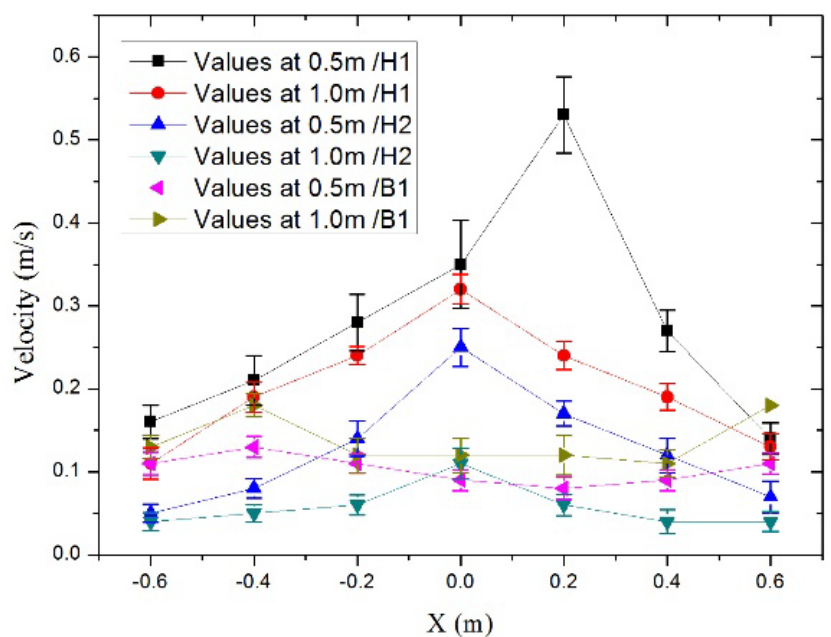

(e)

Fig. 6. Comparison of targeted parameters generated from a single hot pot/steel grill among Restaurants $\mathrm{H} 1, \mathrm{H} 2$ and $\mathrm{B} 1$ : (a) temperature, (b) relative humidity, (c) $\mathrm{CO}$ concentration, (d) $\mathrm{CO}_{2}$ concentration and (e) velocity. 


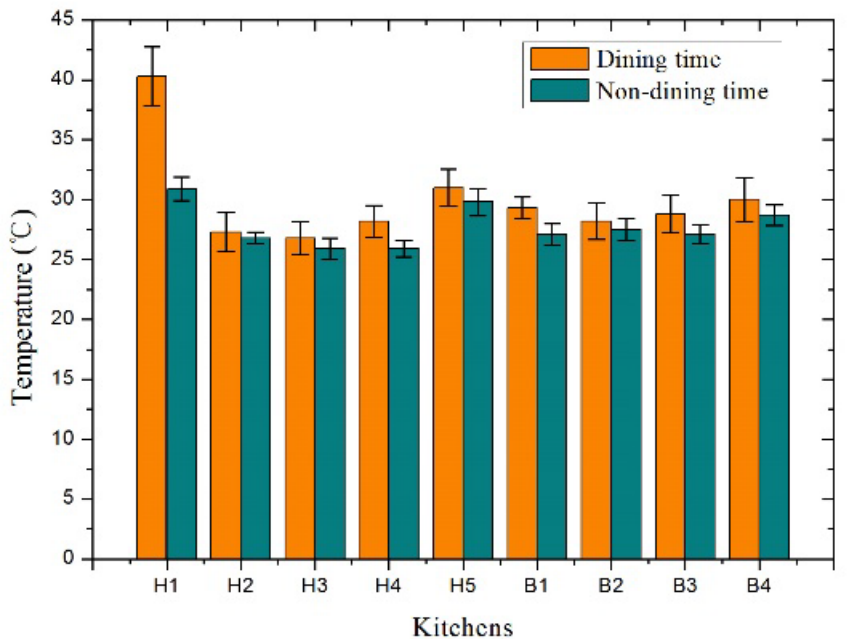

(a)

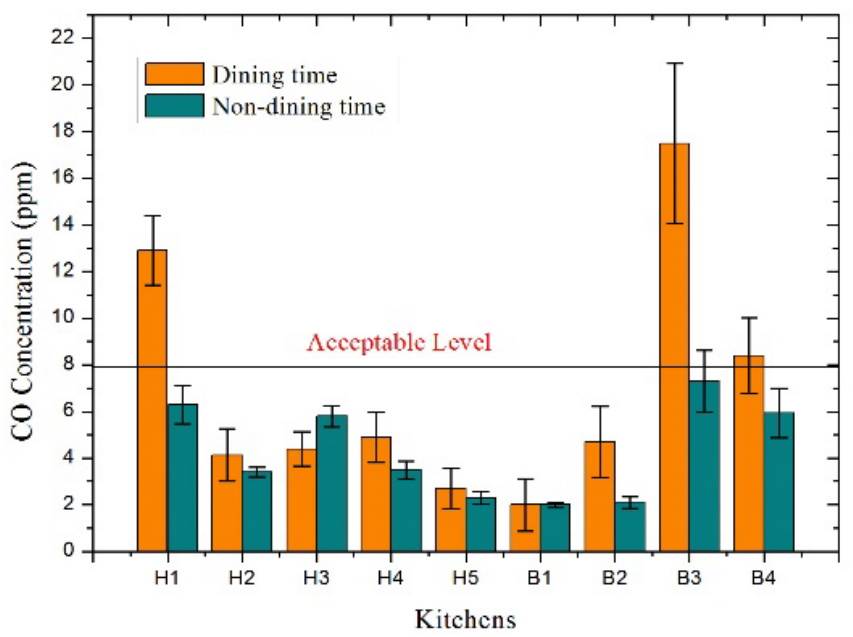

(c)

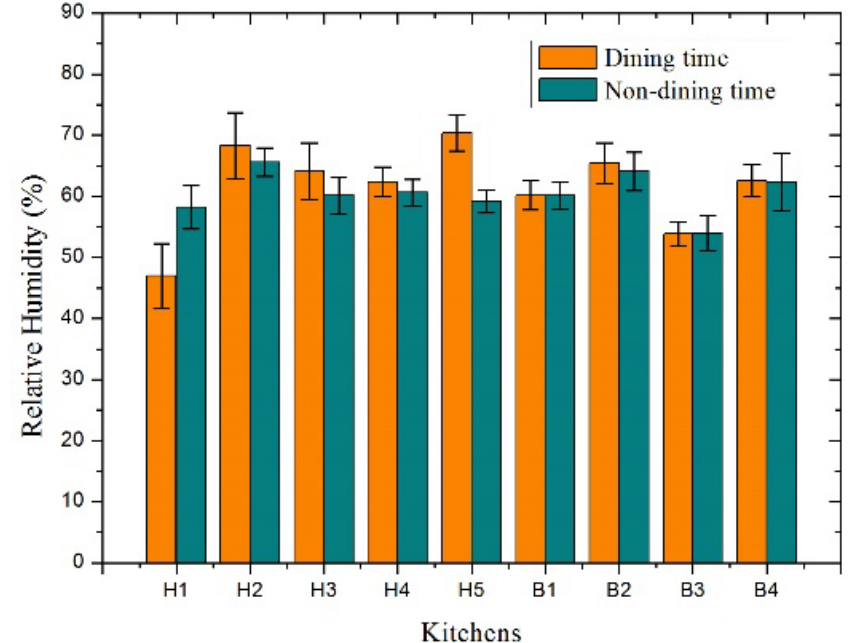

(b)

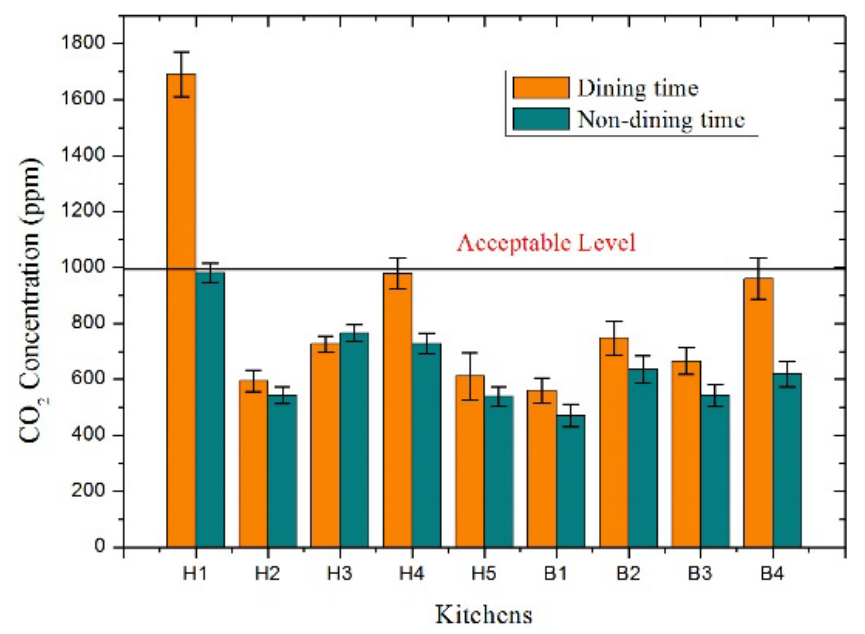

(d)

Fig. 7. Comparison of indoor levels of the targeted parameters generated from different dining kitchens: (a) temperature, (b) relative humidity, (c) $\mathrm{CO}$ concentration and (d) $\mathrm{CO}_{2}$ concentration.

system. As shown in Fig. 7(a), a significant difference was observed between the mean temperatures of the hot working areas before and after cooking. In Kitchen $\mathrm{H} 2$, no heavy load cooking operations were employed; thus, the temperature increase was the minimum. The largest increase in temperature of Kitchen $\mathrm{H} 1$ was related to the boiling of hot pot broth with four gas stores, where the peak temperature was $45.9^{\circ} \mathrm{C}$. For the California Energy Commission (CEC) study, a thermally neutral temperature is $23.9^{\circ} \mathrm{C}$. If the temperature in the space increases by $5.5^{\circ} \mathrm{C}$ above the comfort level, the productivity may decrease as much as $30 \%$ (Chen et al., 2001). Thus, the bad thermal environment in Kitchen $\mathrm{H} 1$ can cause high labor costs. Fig. 7(b) revealed that the mean relative humidity of cooking mode differed from the idle mode in hot working areas. This difference was primarily related to the cooking method. In Kitchen H5, small fire was used to boil the broth. Due to evaporation, the relative humidity value was increased. However, in Kitchen H1, a large fire was used to boil the broth with a gas stove. The relative humidity was reduced due to high temperature and high radiation.
From Fig. 7(c), we were able to determine that the CO concentration in restaurants was primarily related to the fuel used in the kitchen. The largest increase in $\mathrm{CO}$ concentration was detected in the kitchen that used charcoal as the fuel (Restaurant B3). Due to the incomplete combustion of charcoal, in the hot working area of Kitchen B3, the local $\mathrm{CO}$ concentration increased to $17.6 \mathrm{ppm}$, which is $9.6 \mathrm{ppm}$ $(120 \%)$ higher than the acceptable level ( $8 \mathrm{ppm})$. The mean $\mathrm{CO}$ concentrations in Kitchens $\mathrm{H} 1$ and $\mathrm{B} 4$ also exceeded the acceptable level by $4.9 \mathrm{ppm}$ and $0.4 \mathrm{ppm}$, respectively. The data shown in Fig. 7(d) revealed that the average $\mathrm{CO}_{2}$ concentrations in all kitchens did not exceed the indoor standard values, with the exception of Kitchen HI. The actual capture velocity of the hood in Kitchen $\mathrm{H} 1$ was only $0.1 \mathrm{~m} \mathrm{~s}^{-1}$, which could not satisfy the design requirements and produces an excessive $\mathrm{CO}_{2}$ concentration. The ventilation system of $\mathrm{H} 3$ in the restaurant failed to turn on in time during non-meal time, and the meal was prepared in kitchen, so the concentration of pollutants in the kitchen during non-dining time was higher than the value of dining time. In addition, 
since there is no local exhaust system in Kitchen H3, it can only rely on general ventilation to remove pollutants, so it is difficult to form the air flow direction from the dining room to the kitchen and form an effective "negative pressure area." So the concentration of pollutants in the dining area during non-dining time was also higher than the value of dining time.

The specific situations of the hot working area in the nine kitchens is described in Fig. 3 to further analyze the characteristics of the indoor environmental quality in these areas. As shown in Fig. 8, the temperature, humidity, and $\mathrm{CO}$ and $\mathrm{CO}_{2}$ concentrations substantially changed due to different positions in Kitchen $\mathrm{H} 1$, which differed from other kitchens. We also determined that the variation in relative humidity was contrary to the trend of temperature, $\mathrm{CO}$ and $\mathrm{CO}_{2}$ concentrations. In this case, the upper body of a chef would be subjected to hot and dry air. Combined with the floor plan, we determined that the steamer at Point A4 in Kitchen H1 was not burning. For this reason, the values of

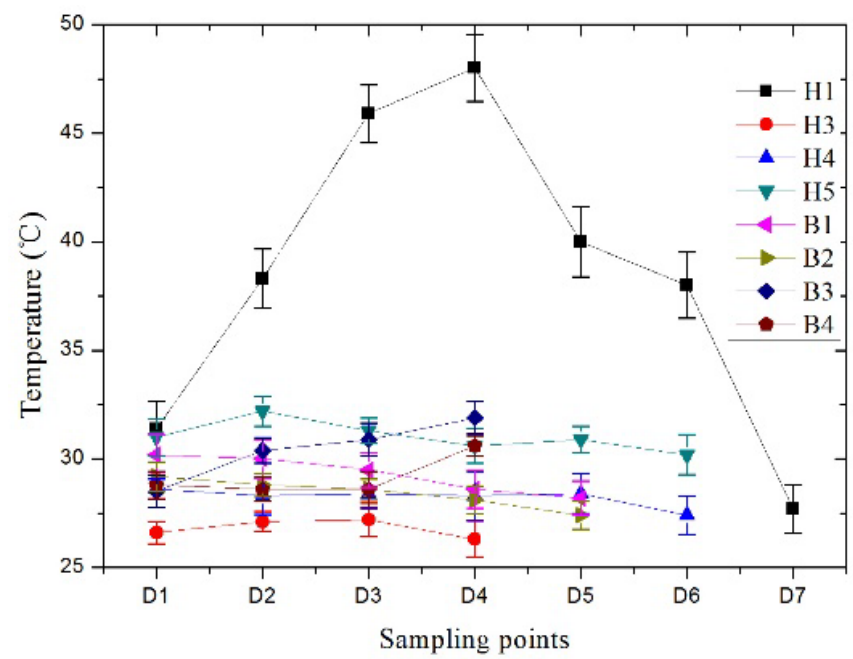

(a)

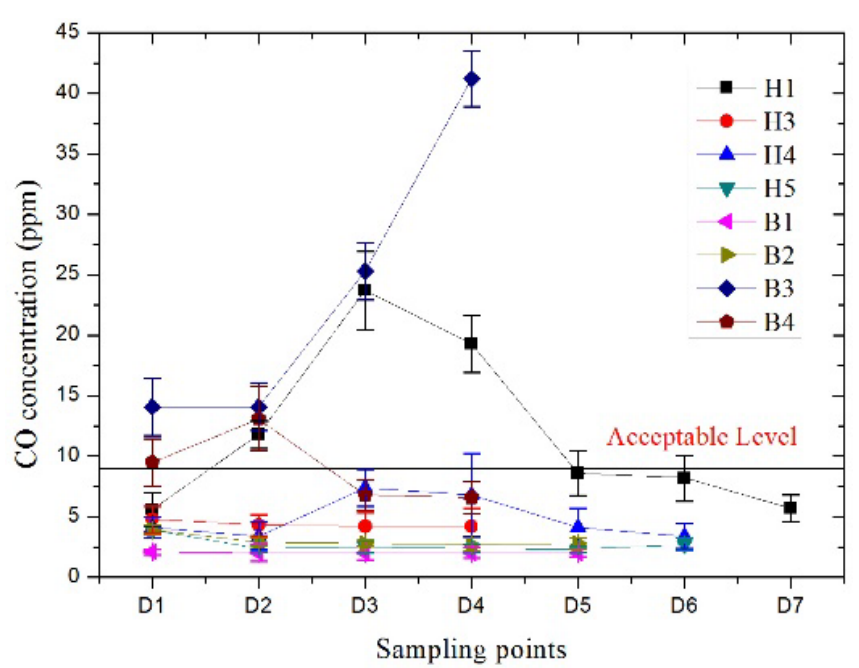

(c) temperature, $\mathrm{CO}$ and $\mathrm{CO}_{2}$ concentrations should not exceed the values of the sampling points for the cooking range that was burning. The results indicated that the air impurities had spread throughout the kitchen, and the capture and containment efficiency of the exhaust hood were questioned. In the Chinese standards, the capture velocity of the hood opening should not be less than $0.5 \mathrm{~m} \mathrm{~s}^{-1}$. In Kitchen H1, the actual capture velocity of the hood was only $0.1 \mathrm{~m} \mathrm{~s}^{-1}$, which explains the poor indoor environmental quality in Kitchen H1. An extremely high value of CO concentration appeared in the hot working area in Kitchen B3, which ranged from 41.2 ppm (Point D4) to $14.1 \mathrm{ppm}$ (Point D1 and D2) among the sampling points. Combined with the floor plan, we observed a charcoal burner range near Point D4, where $50 \mathrm{~kg}$ of charcoal were burned every meal to prepare the steel-pangrilled fish. These situations contributed to the poor indoor air quality.

In these case-study restaurants, the designed exhaust air flow rates were larger than the supply air flow rate, which

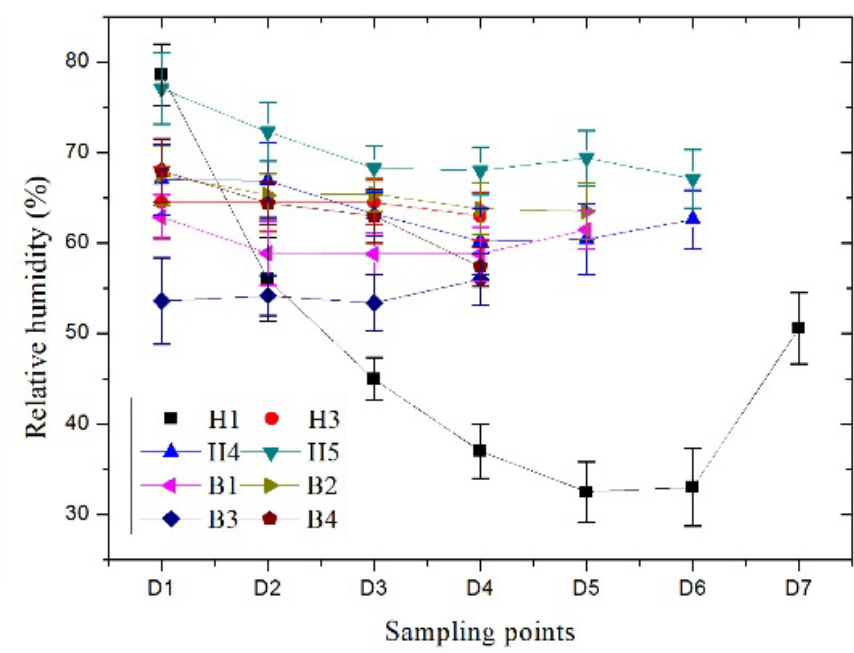

(b)

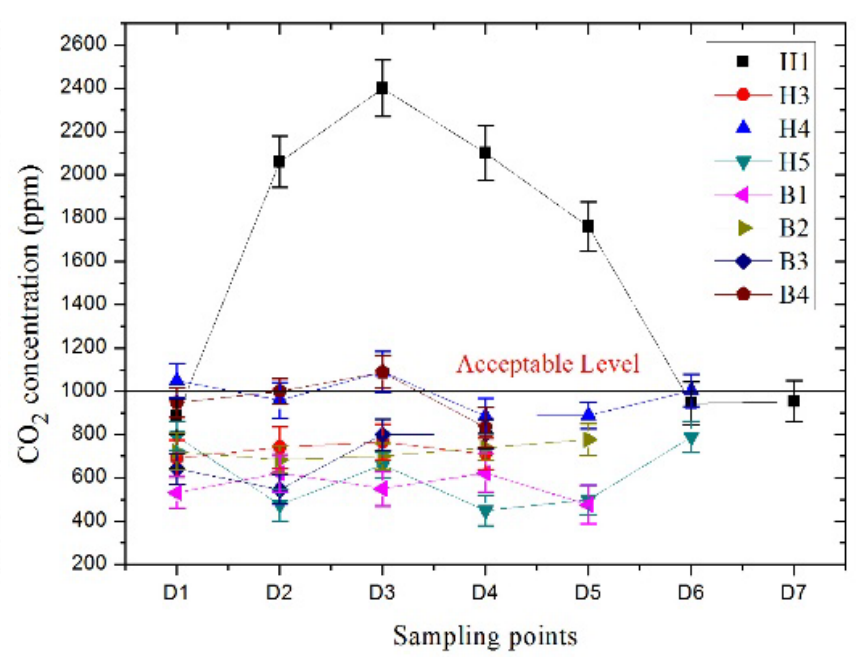

(d)

Fig. 8. Comparison of targeted parameters generated from the different hot working areas: (a) temperature, (b) relative humidity, (c) $\mathrm{CO}$ concentration and (d) $\mathrm{CO}_{2}$ concentration. 
produced a negative pressure in the restaurants. In the kitchen, the make-up air primarily infiltrated the interior door between the dining area and the kitchen because the windows were closed. Thus, the indoor thermal environment in the kitchen was related to the indoor environmental quality in the dining area. The kitchen ventilation system had an important effect on the environmental quality in the dining area. When the exhaust ventilation in the kitchen is not sufficient, contaminants will overflow from the kitchen and enter the dining area through the interior door. By dimensionless analysis, a correlation for the contaminants in the restaurants is obtained in Fig. 9. This correlation indicates a similar trend in the $\mathrm{CO}$ and $\mathrm{CO}_{2}$ concentrations between the dining area and the hot working area in the kitchen. Some differences were observed between the $\mathrm{CO}$ and $\mathrm{CO}_{2}$ concentrations, especially for Restaurant B3. The deviations can be attributed to the fuel used in restaurants. Charcoal was the main fuel in Restaurant B3, where the incomplete combustion of charcoal produced a substantially high concentration of CO. For other restaurants that use gas, electricity or solid alcohol as fuel, the range of change of $\mathrm{CO}$ and $\mathrm{CO}_{2}$ concentrations were almost consistent. In the following study, $\mathrm{CO}_{2}$ was chosen as the main contaminant for evaluating the performance of the kitchen ventilation systems because the changes in concentration were considerable.

\section{Assessment of Ventilation Mode}

In the following section, we discuss our attempts to evaluate the ventilation mode and poor air distribution through the measurement parameters. We employed two evaluation indicators: contaminant removal efficiency (CRE) and efficiency of heat removal (EHR):

\section{Contaminant Removal Efficiency (Yaglou and Witheridge 1937)}

One of the first indicators that actually define a perceived air quality is the contaminant removal effectiveness:

$\varepsilon=\frac{C_{e}-C_{s}}{C-C_{s}}$

This indicator is based on the room average contaminant concentration, $\bar{C}$, the contaminant concentration at supply, $C_{s}$, and the contaminant concentration at exhaust, $C_{e}$. As an indoor air quality indicator, $\varepsilon$ provides more informative results for the removal of contaminants with known position (Atila and Jelena, 2003).

\section{Efficiency of Heat Removal (Awbi and Gan, 1993)}

When waste heat is regarded as a contaminant, we can obtain the efficiency of heat removal, which is also known as the energy utilization coefficient. This coefficient is defined by temperature, which is used to examine the ventilation effectiveness for the heat removal:

$\eta_{t}=\frac{t_{e}-t_{s}}{\bar{t}-t_{s}}$

This indicator is based on the room average temperature

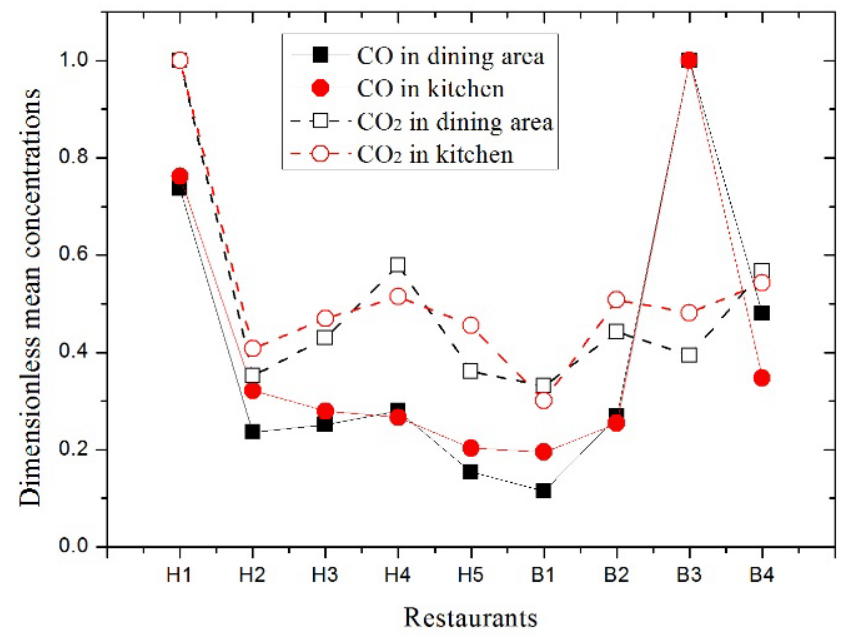

Fig. 9. Comparison of $\mathrm{CO}$ and $\mathrm{CO}_{2}$ concentrations in the sampled restaurants during meal time.

$\bar{t}$, the temperature at supply $t_{s}$, and the temperature at exhaust $t_{e}$. When $\bar{t}<t_{e}, \eta_{t}>1$; otherwise, $\eta_{t}<1$. The larger is $\eta_{t}$, the higher is the energy utilization of this air distribution.

As shown in Table 7, the highest contaminant removal efficiency of the dining areas was 1.16 in Restaurant B1, whereas the lowest contaminant removal efficiency of the dining areas was 0.46 in Restaurant H1. Due to the side exhaust system on edges in Restaurants H2, B1 and B2, all contaminant removal efficiencies exceeded 0.83 . The energy utilization coefficient of the dining areas ranged from 0.87 (H1) to 1.22 (B1). In the dining area, even the air conditioning system can provide adequate cooling capacity, and the ability to eliminate contaminants was questioned.

The data in Table 7 showed that the highest contaminant removal efficiency of the hot working area in Kitchen B1 was 1.07. The lowest contaminant removal efficiency in Kitchen $\mathrm{H} 1$ was 0.50 . Kitchens $\mathrm{H} 2$ and $\mathrm{H} 3$ did not have a local exhaust system; thus, the contaminant removal efficiency was representative of the general ventilation system. For other kitchens, the contaminant removal efficiency had a significant correlation to the capture efficiency of the exhaust hood. One of the important factors that affect the capture efficiency of the exhaust hood is the surface air velocity. In Kitchen H1, the main reason for low contaminant removal efficiency was that the surface air velocity of the exhaust hood was only $0.1 \mathrm{~m} \mathrm{~s}^{-1}$, which did not meet the design requirement of $0.5 \mathrm{~m} \mathrm{~s}^{-1}$. The highest energy utilization coefficient of the kitchens of 1.03 was achieved in Restaurant B1, whereas the lowest energy utilization coefficient of 0.57 was achieved in Restaurant H1.

\section{DISCUSSION}

In contrast from the general-style restaurants, in Chinese hot pot and barbecue restaurants, the dining process and cooking process are simultaneously performed. The dining area is equivalent to the kitchen, and the diner is equivalent to the chef. Air pollutants, waste heat, water vapor, and odors that were generated during the eating process were 
Table 7. Comprehensive assessment of the dining areas in sampled restaurants.

\begin{tabular}{lllllllllll}
\hline & & $\mathrm{H} 1$ & $\mathrm{H} 2$ & $\mathrm{H} 3$ & $\mathrm{H} 4$ & $\mathrm{H} 5$ & $\mathrm{~B} 1$ & $\mathrm{~B} 2$ & $\mathrm{~B} 3$ & $\mathrm{~B} 4$ \\
\hline Dining area & $\bar{C}(\mathrm{ppm})$ & 1672.9 & 682.2 & 785.9 & 861.8 & 762.2 & 496.2 & 844.3 & 803.2 & 908.5 \\
& $C_{s}(\mathrm{ppm})$ & 382 & 420 & 410 & 397 & 403 & 455 & 453 & 412 & 437 \\
& $C_{e}(\mathrm{ppm})$ & 981 & 637 & 750 & 803 & 724 & 503 & 825 & 776 & 843 \\
& $\varepsilon$ & $\mathbf{0 . 4 6}$ & $\mathbf{0 . 8 3}$ & $\mathbf{0 . 9 0}$ & $\mathbf{0 . 8 7}$ & $\mathbf{0 . 8 9}$ & $\mathbf{1 . 1 6}$ & $\mathbf{0 . 9 5}$ & $\mathbf{0 . 9 3}$ & $\mathbf{0 . 8 6}$ \\
& $\bar{t}\left({ }^{\circ} \mathrm{C}\right)$ & 25.4 & 27.7 & 26.0 & 25.5 & 26.0 & 28.7 & 24.8 & 24.7 & 27.1 \\
& $t_{s}\left({ }^{\circ} \mathrm{C}\right)$ & 23.0 & 23.0 & 23.0 & 23.0 & 23.0 & 23.0 & 20.0 & 20.0 & 23.0 \\
& $t_{e}\left({ }^{\circ} \mathrm{C}\right)$ & 25.1 & 27.2 & 26.0 & 25.4 & 25.8 & 30.0 & 24.9 & 25.3 & 26.9 \\
& $\eta_{t}$ & $\mathbf{0 . 8 7}$ & $\mathbf{0 . 8 9}$ & $\mathbf{1 . 0 0}$ & $\mathbf{0 . 9 6}$ & $\mathbf{0 . 9 3}$ & $\mathbf{1 . 2 2}$ & $\mathbf{1 . 0 2}$ & $\mathbf{1 . 1 2}$ & $\mathbf{0 . 9 5}$ \\
& $\bar{C}(\mathrm{ppm})$ & 1691.2 & 595.4 & 726.8 & 979.3 & 610.8 & 560.0 & 747.8 & 654.2 & 960.2 \\
& $C_{s}(\mathrm{ppm})$ & 382 & 420 & 410 & 397 & 403 & 455 & 453 & 412 & 437 \\
& $C_{e}(\mathrm{ppm})$ & 1040 & 550 & 684 & 830 & 648 & 567 & 738 & 625 & 834 \\
& $\varepsilon$ & $\mathbf{0 . 5 0}$ & $\mathbf{0 . 7 4}$ & $\mathbf{0 . 8 6}$ & $\mathbf{0 . 7 4}$ & $\mathbf{0 . 9 3}$ & $\mathbf{1 . 0 7}$ & $\mathbf{0 . 9 7}$ & $\mathbf{0 . 8 8}$ & $\mathbf{0 . 7 6}$ \\
& $\bar{t}\left({ }^{\circ} \mathrm{C}\right)$ & 40.3 & 27.3 & 26.8 & 28.2 & 31.0 & 29.3 & 28.2 & 28.3 & 30.0 \\
& $t_{s}\left({ }^{\circ} \mathrm{C}\right)$ & 23.0 & 23.0 & 23.0 & 23.0 & 23.0 & 23.0 & 20.0 & 20.0 & 23.0 \\
& $t_{e}\left({ }^{\circ} \mathrm{C}\right)$ & 33.5 & 27.2 & 26.4 & 28.0 & 30.5 & 29.5 & 27.7 & 27.7 & 29.3 \\
& $\eta_{t}$ & $\mathbf{0 . 5 7}$ & $\mathbf{0 . 9 8}$ & $\mathbf{0 . 8 9}$ & $\mathbf{0 . 9 6}$ & $\mathbf{0 . 9 4}$ & $\mathbf{1 . 0 3}$ & $\mathbf{0 . 9 4}$ & $\mathbf{0 . 9 3}$ & $\mathbf{0 . 9}$ \\
\hline
\end{tabular}

released into the indoor air. Heat exposure and pollution exposure to personnel are extremely serious because people sit around the cooking sources throughout meal time. This type of restaurant often arranged dozens of cooking sources in the dining area. Hundreds of people eat together.

The results indicated that the $\mathrm{CO}$ concentration fueled with charcoal was the highest in the dining area, whereas the $\mathrm{CO}_{2}$ concentration fueled with gas was the highest. This finding is consistent with the study conducted by Lee et al. (2001) and Chen et al. (2007) for some restaurant environments. When the local exhaust system was present, the indoor pollutants in the dining area could be effectively reduced. However, the premise was that the kitchen's local ventilation system would operate well because the local exhaust hood creates negative pressure in the kitchen and the make-up air predominantly originated in the dining area through a passthrough window or door. The ventilation rate of all the restaurants is based on the same air change rate; however, in actuality, the ventilation system is difficult to meet the design requirements, especially the local exhaust system in the kitchen. Due to improper operation adjustment (some kitchens only open the exhaust system during peak dining time), grease blockage and unreasonable pipeline design, the local exhaust ventilation rate may exceed or fall below the design value. If the actual local exhaust ventilation rate is too low, it will lead to positive pressure in the kitchen, making cooking pollutants escape the kitchen and affect the indoor air quality in the dining room. On the contrary, if the actual exhaust air is too high, it will lead to higher operating energy consumption. The connection between the ventilation systems in the kitchen and the dining area of the hot pot and barbecue restaurants had been neglected.

During a meal, the temperature change in the dining area was small, and the relative humidity significantly increased. The air conditioning system was able to provide sufficient cooling capacity in the hot pot and barbecue restaurants. However, the system lacked the ability to eliminate moisture and pollutants. The traditional mixed ventilation system that is based on the dilution principle aims to satisfy people's thermal comfort and hygiene requirements. Regardless of the location of indoor pollution sources and the personnel distribution, the importance of the occupied zone, which requires a large amount of ventilation, applies to all restaurants. In many cases, not only the problem of poor indoor air quality but also the initial investment and operating costs of the entire ventilation system are increased, which causes unnecessary economic waste (Gao et al., 2014). In previous studies, we discussed the reasons for poor thermal environments in kitchens and unsuitable mixed ventilation systems ( $\mathrm{Li}$ et al., 2012). In this research, we determined that a mixed ventilation system is not suitable for the dining areas of hot pot and barbecue restaurants for the following reasons.

1. The unwanted air movement and cross-drafts created by the high discharge velocity from mixing diffusers generates pollution that gathers at the top of a restaurant (dining area or kitchen) and extends to the breathing zone. Human exposure to pollutants is increased due to the poor air distribution.

2. All heat and pollutants from multiple heat sources in the restaurant (dining area or kitchen) are mixed within a space, which hinder the capture of the plumes from cooking sources with an exhaust air flow or hood.

Compared to a kitchen, the indoor environment in a dining area deserves more attention due to the highly intensive cooking sources. The actual distribution of the cooking sources in the dining area must be considered to ensure that contaminants can be effectively eliminated during meal time and fresh air can be efficiently delivered to the sitting area. In this study, the side exhaust system that is placed on the edge of a table can effectively reduce the exposure to pollutants; however, the energy consumption was immense. The air volume used for the side exhaust system exceeded $80 \%$ of the total exhaust air volume of the dining area. A more suitable ventilation mode for hot pot and barbecue restaurants is needed. Similar to the kitchen, the thermal plumes and cooking fumes that are generated during eating hot pot and barbecue flow upward. As a reference for kitchen ventilation, the displacement ventilation combined with a 
local exhaust system, which warrant further investigation, may be a suitable system for this type of restaurant (Li et al., 2012).

\section{CONCLUSIONS}

The indoor environmental quality of hot pot and barbecue restaurants, where cooking and dining simultaneously occur, has attracted growing public concern. Thus, this paper presents an integrated evaluation of the conditions and ventilation systems in five commercial hot pot restaurants and four barbecue restaurants in China. The environment in the dining area was influenced by the cooking fuel and the mechanical exhaust systems, especially the local one. Although the relative humidity in the dining areas significantly increased following a meal, the mean temperature showed minimal difference. Restaurant B3, which used charcoal as the cooking fuel, and Restaurant $\mathrm{H} 1$, which used natural gas, exhibited the highest mean $\mathrm{CO}(11.8 \mathrm{ppm})$ and $\mathrm{CO}_{2}$ (1673.2 ppm) concentrations, respectively. In restaurants that had installed a local exhaust ventilation system beneath the dining table (where the heat source was located), the temperature and contaminant levels above the table remained relatively low and consistent throughout the meal. On the other hand, the environment in the cooking area of the kitchen depended on the fuel, cooking method and hood exhaust system.

In general, as with other types of restaurants, charcoal burning and natural gas combustion were associated with increases in $\mathrm{CO}$ and $\mathrm{CO}_{2}$, respectively. Various cooking patterns caused different heat and humidity loads. Owing to the low contaminant removal and heat removal efficiencies of the ventilation system, the average temperature, and $\mathrm{CO}$ and $\mathrm{CO}_{2}$ concentrations in the cooking area of Restaurant $\mathrm{H} 1$ were $40.3^{\circ} \mathrm{C}$, and $12.9 \mathrm{ppm}$ and $1691.2 \mathrm{ppm}$, respectively. Additionally, the relative humidity was $47.0 \%$, and the capture and containment efficiencies of the exhaust hood were found to fall short of the standard.

Overall, the use of charcoal in indoor restaurants should be reduced, and a clean alternative, such as electricity, should be employed. To ensure that the kitchens exhaust a sufficient volume of air, local exhaust systems should be installed. However, determining the most suitable air distribution system requires further investigation.

\section{ACKNOWLEDGEMENT}

All authors contributed equally to the preparation of this manuscript. We are grateful to Haoran Jin and Zhenhao Zhang for their assistance with the field test. This research was supported by the Scientific Research Program funded by the Shaanxi Provincial Education Department (No. 19JK0543), the Natural Science Basic Research Plan of Shaanxi Province of China (No. 2020JQ-750) and the Scientific Research Program funded by Xi'an Science and Technology Bureau (No. 201805036YD14CG20(5)).

\section{REFERENCES}

Atila, N. and Jelena, S. (2003). Comparison of air exchange efficiency and contaminant removal effectiveness as IAQ Indices. ASHRAE Trans. 109: 339-349.

Awbi, H.B. and Gan, G. (1993). Evaluation of the overall performance of room air distribution. Indoor Air 5: 283288.

Cao, G., Awbi, H., Yao, R., Fan, Y.Q., Sirén, K., Kosonen, R. and Zhang, J.S. (2014). A review of the performance of different ventilation and airflow distribution systems in buildings. Build. Environ. 73: 171-186. https://doi.org/10. 1016/j.buildenv.2013.12.009

Chen, C.T., Kuo, Y.C., Wang, S.M., Wu, K.R., Chen, Y.C. and Tsai, P.J. (2019). Techniques for predicting exposures to polycyclic aromatic hydrocarbons (PAHs) emitted from cooking processes for cooking workers. Aerosol Air Qual. Res. 19: 307-317. https://doi.org/10.4209/aaqr.201 8.09.0346

Chen, J., Duffy, B., Fletcher, D.F., Haynes, B.S. and Nelson, P. (2001). FTIR spectroscopy measurements and CFD simulations of the pollutants arising from unfueled combustion in a room. Build. Environ. 36: 597-603. https://doi.org/10.1016/s0360-1323(00)00037-8

Chen, W.H., Wang P., Zhang D.C., Liu J.J., Dai X.L. (2020). The impact of water on particle emissions from heated cooking oil. Aerosol Air Qual. Res. 20: 533-543. https://doi.org/10.4209/aaqr.2019.09.0427

Chen, Y.L., Chen C., Yu, S.P., Gao, N. and Zhou, C.J. (2007). Indoor air pollution survey in hot pot restaurants, J. Environ. Health 24: 524-526. (in Chinese)

Cheng, J.H., Lee, Y.S. and Chen, K.S. (2016). Carbonyl compounds in dining areas, kitchens and exhaust streams in restaurants with varying cooking methods in Kaohsiung, Taiwan. J. Environ. Sci. 4: 218-226. https://doi.org/10.10 16/j.jes.2015.06.006

Claeys, B., Laverge, J., Pollet, I. and Bryuneel, G. (2015). Performance testing of air curtains in residential range hoods. Procedia Eng. 121: 199-202. https://doi.org/10.10 16/j.proeng.2015.08.1052

de la Sota, C., Viana, M., Kane, M., Youm, I., Masera, O. and Lumbreras, J. (2019). Quantification of carbonaceous aerosol emissions from cookstoves in Senegal. Aerosol Air Qual. Res. 19: 80-91. https://doi.org/10.4209/aaqr.20 17.11 .0540

GB/T 18883-2002. (2003). Indoor air quality standard of China. China Planning Press, Beijing.

He, L.Y., Hu, M., Huang, X.F., Yu, B.D., Zhang, Y.H. and Liu, D.Q. (2004). Measurement of emissions of fine particulate organic matter from Chinese cooking. Atmos. Environ. 38: 6557-6564. https://doi.org/10.1016/j.atmos env.2004.08.034

Huang, H.L., Lee, W.M.G. and Wu, F.S. (2016). Emissions of air pollutants from indoor charcoal barbecue. $J$. Hazard. Mater. 302: 198-207. https://doi.org/10.1016/j.j hazmat.2015.09.048

IARC Working Group on the Evaluation of Carcinogenic Risks to Humans. (2010). Household use of solid fuels and high-temperature frying. IARC Monogr. Eval. Carcinog. Risks Hum. 95: 1-430.

Karimatu, L.A., Juana, M.D.S. and Roy, M.H. (2013). Emissions and indoor concentrations of particulate matter 
and its specific chemical components from cooking: A review. Atmos. Environ. 71: 260-294. https://doi.org/10.1 016/j.atmosenv.2013.01.061

Keil, C.B., Kassa, H. and Fent, K. (2004). Kitchen hood performance in food service operations. J. Environ. Health 67: 25-30.

Kosonen, R. (2007). The effect of supply air systems on the efficiency of a ventilated ceiling. Build. Environ. 42: 16131623. https://doi.org/10.1016/j.buildenv.2005.09.030

Lee, S.C., Li, W.M. and Chan, L.Y. (2001). Indoor air quality at restaurants with different styles of cooking in metropolitan Hong Kong. Sci. Total Environ. 279: 181193. https://doi.org/10.1016/s0048-9697(01)00765-3

Levy, J.I., Dumyahn, T. and Spengler, J.D. (2002). Particulate matter and polycyclic aromatic hydrocarbon concentrations in indoor and outdoor microenvironments in Boston, Massachusetts. J. Exposure Sci. Environ. Epidemiol. 12: 104-114. https://doi.org/10.1038/sj.jea.7500203

Li, A., Zhao, Y., Jiang, D. and Hou, X.T. (2012). Measurement of temperature, relative humidity, concentration distribution and flow field in four typical Chinese commercial kitchens. Build. Environ. 56: 139150. https://doi.org/10.1016/j.buildenv.2012.03.001

Li, A., Zhao, Y., Wang, Z.H. and Gao, R. (2014). Capture and containment efficiency of the exhaust hood in a typical Chinese commercial kitchen with air curtain ventilation. Int. J. Vent. 13: 221-234. https://doi.org/10.1 080/14733315.2014.11684050

Lim, K. and Lee, C. (2008). A numerical study on the characteristics of flow field, temperature and concentration distribution according to changing the shape of separation plate of kitchen hood system. Energy Build. 40: 175-184. https://doi.org/10.1016/j.enbuild.2007.02.028

Livchak, A., Schrock, D. and Sun, Z. (2005). The effect of supply air systems on kitchen thermal environment. ASHRAE Trans: 111: 748-754.

Ni, K., Carter, E. and Schauer, J.J. (2016). Seasonal variation in outdoor, indoor, and personal air pollution exposures of women using wood stoves in the Tibetan Plateau: Baseline assessment for an energy intervention study. Environ. Int. 94: 449-457. https://doi.org/10.1016/j. envint.2016.05.029

Que, D.E., Chao, H.R., Hsu, Y.C., Cui, K., Chen, S., Tayo, L.L., Arcega, R.D., Tsai, Y.I., Lu, I.C., Wang, L.C., Young, L.H., Yu, K.L.J., Lai, C.Y., Hou, W.C. and Lin, S.L. (2019). Emission of carbonyl compounds from cooking oil Fumes in the night market areas. Aerosol Air Qual. Res. 19: 1566-1578. https://doi.org/10.4209/aaqr.2 019.06.0289

Saha, S., Guha, A. and Roy S. (2012). Experimental and computational investigation of indoor air quality inside several community kitchens in a large campus. Build. Environ. 52: 177-190. https://doi.org/10.1016/j.buildenv. 2011.10.015

Simone, A., Olesen, B.W., Stoops, J.L. and Watkins, A.W. (2013). Thermal comfort in commercial kitchens (RP1469): Procedure and physical measurements (Part 1). HVAC\&R Res. 19: 1001-1015. https://doi.org/10.1080/1 0789669.2013.840494
State Administration of Work Safety (2016). Technical specifications for test and evaluation of capture velocity for local exhaust ventilation facilities. China planning press, Beijing.

Susaya, J., Kim, K.H., Ahn, J.W., Jung, M.C. and Kang, C.H. (2010). BBQ charcoal combustion as an important source of trace metal exposure to humans. J. Hazard. Mater. 176: 932-937. https://doi.org/10.1016/j.jhazmat.2 009.11.129

Swierczyna, R., Sobiski, P. and Fisher, D. (2016). Effects of appliance diversity and position on commercial kitchen hood performance. ASHRAE Tran. 112: 591-602.

Tsai, F.C. and Hsieh, R.H. (2016). Oblique effects on the capture ability of a hood under crosswind environmentsnumerical method. Build. Environ. 41: 1471-1477. https://doi.org/10.1016/j.buildenv.2005.05.032

Vicente, E.D., Vicente, A., Evtyugina, M., Carvalho, R., Tarelho, L.A.C., Oduber, F.I. and Alves, C. (2018). Particulate and gaseous emissions from charcoal combustion in barbecue grills. Fuel Process. Technol. 176: 296-306. https://doi.org/10.1016/j.fuproc.2018.03.004

Wang, C., Liu, L., Liu, X., Chen, W. and He, G. (2017a). Mechanisms of lung cancer caused by cooking fumes exposure: a minor review. Chin. Med. Sci. J. 32: 193-197. https://doi.org/10.24920/J1001-9294.2017.026

Wang, L., Xiang, Z., Stevanovic, S., Ristovski, Z., Salimi, F., Gao, J., Wang, H.L. and Li, L. (2017b). Role of Chinese cooking emissions on ambient air quality and human health. Sci. Total Environ. 589: 173-181. https://doi.org/10.1016/j.scitotenv.2017.02.124

World Health Organization (WHO) (2015). Public health, environmental and social determinants of health (PHE) events during the 68th world health assembly. Geneva.

Yaglou, C.P. and Witheridge, W.N. (1937). Ventilation requirements, Part 2. ASHRAE Trans. 42: 423-436.

Zhang, N., Han, B., He, F., Xu, J., Zhao, R.J., Zhang, Y.J. and Bai, Z.P. (2017). Chemical characteristic of $\mathrm{PM}_{2.5}$ emission and inhalational carcinogenic risk of domestic Chinese cooking. Environ. Pollut. 227: 24-30. https://doi.org/10.1016/j.envpol.2017.04.033

Zhao, Y., Li, A.G, Tao, P.F. and Gao. R. (2013). The impact of various hood shapes, and side panel and exhaust duct arrangements on the performance of typical Chinese style cooking hoods. Build. Simul. 6: 139-149. https://doi.org/10.1007/s12273-012-0096-1

Zhao, Y., Liu, L., Tao, P., Zhang, B., Huan, C., Zhang, X. and Wang, M. (2019). Review of effluents and health effects of cooking and the performance of kitchen ventilation. Aerosol Air Qual. Res. 19: 1937-1959. https://doi.org/10.4209/aaqr.2019.04.0198

Zhou, B., Chen, F., Dong, Z.B. and Nielsen, P.V. (2016). Study on pollution control in residential kitchen based on the push-pull ventilation system. Build. Environ. 107: 99112. https://doi.org/10.1016/j.buildenv.2016.07.022

Received for review, September 18, 2020 Revised, October 12, 2020 Accepted, October 16, 2020 